- LA-GA $-84-512$

- CONF-840256.-1

\title{
DISCLAIMER
}

\begin{abstract}
This report wa prepared as an account of work sponcored by an asency of the United Statee Governmont. Nolther the Unilod Stutes Government nor any agoncy thereof, nor any of their employees, makes any wartanty, express or implied, or esumes any legal liability of reaponet. blitty for the sccuracy, completenest, or usefulneas of any information, apparatue, product, of procoses dieclowed, of ropresents that lte use would not infringe privalely owned rights. Roforenee herein to any spectifs commercial product, procest, of cervice by trade name, trademarts,

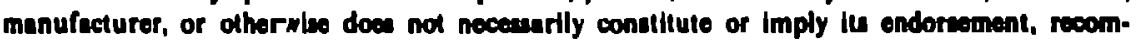
mendation, of favortse by the United States Government or any agency thereof. The viom and opintons of authori expreased heioln do not neceunarly state or reflect those of the United States Government or any agency theroof.
\end{abstract}

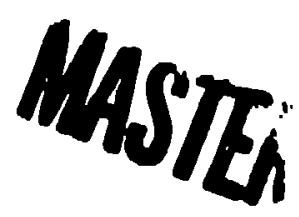

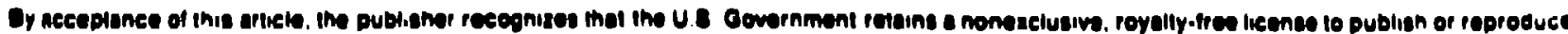

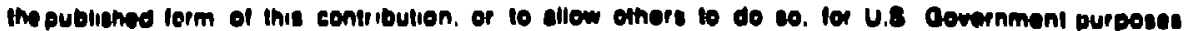




\section{MICROTHEORY OF COLLISIONLESS SHOCK CURRENT LAYERS}

\section{Winske}

Los Alamos National Laboratory, Lor Alamo8, NM 87545

\section{Abstract}

The present status of understanding of microscopic dissipation processes in the current layer of collisionless shocks is revlewed. The emphasis is on cross-field current-driven instabilities and their Importance in quasiperpendlcular shocks, although other processes which arlse in quasiparallel shocks are also discussed. A general prescription is given for calculating turbulent heating and resistivity in shocks.

\section{Introduction}

In collisionless shocks the directed flow energy in the ipstreaw region is converted to thermal energy in the downstream region over distances that are much shorter than the clasolcal mean free path of the flowing particles. A good example of such shocks is the earth's bow shock, where the scale length of the transition region between the upstream and downstream states is less than several hundred kllometers, while the mean free path of the solar wind lons 18 on the order of $1.0^{7}$ kllometers (e.8., see revlews by Greenstadt and Fredrlcks (1979) and Kennel (this meeting)). The bow shock transition is very distinct, and thus most easily seen, near the portion of the shock where the upstream magnot1c fleld is nearly perpendicular to the shock normal ("perpendicular shock"). In contrast, near the portion of the shock where the shock normal and upstream magnetic fleld are nearly parallel ("parallel shock"), the transition is obscured by large magnetic fleld fluctuations which extend for thousands of kilometers upstream and downstream from the polnt where the plasma properties change abruptly. It has been recognized for many years that the "collisionless" process by which some of the flow enerzy is dissipated is due to the Interaction of the solar wind parilcles with plasma waves generated as a result of microinstablilties which arise because of various sources of free energy in the system (e.g., relative drifte between the plasma components, non-Maxwellian velocity distributions, gradients in density, temperature, magnetic fleld, etc.). The sudy of dissipation processes in collisionless shocks then has been aimed at ldentifyling the possible sources for instablilties, wurking out the properties of the unstable modes (both in their linear and nonlinear behavior) a id then analyzing their effects on the plasma in terms of bulk heating and particle acceleration and on the current and fleld structure in terms of an "anomalous" resistivity.

A number of good reviews of dissipation processes in shocks alrendy exist. The state of the art up to 19731 s best cummarized in the art1cle of Blakcop (1973), a very thurough review of all aspects of coll1sionless shocks. Instablilties related to the earth" bow shock heve been consldered by Greenstadt and Fredillok (1974). Galeev (1976) has reviewed the subject of huating in collisionless shocks, eapecially with regard to ton sound turbulence. Papadopoulos (1977) has discussed the Instabilities which develnp from a current along a manetic fleld with applications to magnctospheric and lonospheric phenomena. Instablities which develop from crosefield currents that occur in laboratory hocks have been considered by Davijson and Krall (1977). 
-. -2-

Wu (1982) has emphasized the underlying physical processes for dissipation ac both quasiparallel and quasiperpendicular shocks with a IImited discuseion of the instablilties themselves. Finally, Wu et al. (1984) have reexamined the instabilitles relevant to quasiperpendicular shocks and updated much of the theory to apply to supercritfcal shocks where reilected lons become important. There are also good discussions In textbooks of Instabilitles (e.g., Krall and Irivelpiece, 1973; Hasegawa, 1975) and thelr effects on shocks, (e.g., Tidman and Kraj.1, 1971).

The purpose of the present review is to update from B1skamp (1973) what 18 known about the varfous instabflities which are thought to be responsible for the dissipation in collisionless shocks. This will Include the current status of the linear, nonlinear, and transport (e.g., heating) properties of the instabllitles in general and with application to shocks in particular. This type of review is needed because much progress has been made in the last decade and many of the resuits are not found in space physics journals. A review of this kind is also appropriate because recent advances in the construction of large computers and formulation of numerical simulation methods (e.g., Implicit codes) make a relnvestigation of some of the unanswered questions feasible today on a scale which would have been impossible ten years ago.

In this review we will restrict our attention primarily to current-driven instabilities in the transition layer. These have been the most widely studied and their importance for dissipation in quasiperpendictiar shocks is well known. Our understanding of dissipation processes (as well as most other phenomena) at quasiparallel shocks is much more rudimentary and will be discussed only brlefiy here. (Also see reviews at this meeting by Greenstadt and Quest). Instabilities and assoriated particle behavior (e.g., acceleration) in the upstream region will be treated in other reviews (e.g., Thomsen, Klimas), as will manifestations of the 1nstabilities (1.e., wave observations, heating as derlved from particle distributions) (Gurnett, Robson).

The plan of this review 18 as follcws. In Sec. II the basic concepts of the Instablil:y analysis are enumerated. The fleld and current structure of quasiperpendicular shock $1 \mathrm{~s}$ first described and the role of plasma instabilities is identifled. The need for wicroturbulent dissipation is then illustrated through observations of plasma heating at ohscks. How the effects of the lnatabilities enter in 18 recalled by mear. of the quasilinear equations for the macroscoplc quantities. A. basic priacription lnvolving four eteps is then lald out. The flrst atep involves the identification of the various instablitites from their ources of free energy (whlch ma; vary across the shock layer) and their categorization into wode types (electromagnetic or electrostatic) and frequency ranges. Linear analyale is the next tep; 1ty espential feetures and ultimate goals are delineated. The third etep 1s nonilnear analyeis. Varlous approeches, Including almulation rethods, are outlined. In the final -tep the resulte of the previous eseps are fed beck into the quasilinear equetione to give rates for plasma heating and expressions for the resistivity. While 1t sounde (and 1o) etrulghtforward, very few calculatione for actial hocko have been done in detall. 
In Sec. III the different steps of thls process are analyzed for varlous modes. First, the lnstabilities are identifled and then subdivided Into high frequency (electrostatic) modes and low frequency (electromagnet1c) modes. The electroscatic modes include the much studied Ion acoustic Instablity and the somewhat neglected electron cyclotron drift instability. The electromagnetic modes considered include the Ion-ion instability, the modified two stream (also known as the kInetic cross-field streaming) instability, and the lower hybrid drift Instablifty. For each Instablilty we sumarize the current state of linear and nonlineas theory, simulations, and transport properties, especially with regard to shock-like geometries. In addition, we brlefiy discuss other Instabilities and dissipation processes which msy contibute, but which have been studied much less thoroughly.

Finally, in Sec. IV we summarlze the overall status of microtheory, where we stand tojay, how far we have advanced in the last ten years, and where we hope to be in the future. We also discuss the strengihs and weaknesses of the present approaches and how they are beins, improved. Finally, we polnt out what is needed to increase our level of understanding of collisionless shocks in the next few years.

\section{Basic Concepts}

A. Notation and geometry

first collect the definitions of the symbols used throughout the text. We let e acharge, mamass, $n_{\alpha}$-density,

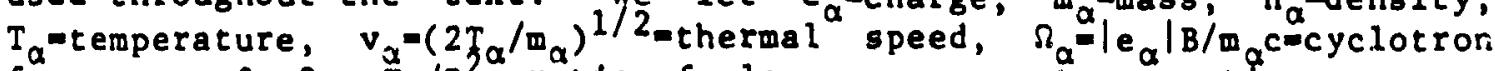
frequency ${ }_{\beta}{ }_{\alpha}=8 \pi n_{\alpha} \mathrm{T}_{\alpha} / \mathrm{B}^{2} \mathrm{r}_{L}{ }^{\alpha}$ lo of plasma pressure to magnet $\mathrm{I}_{c}$ pressure,

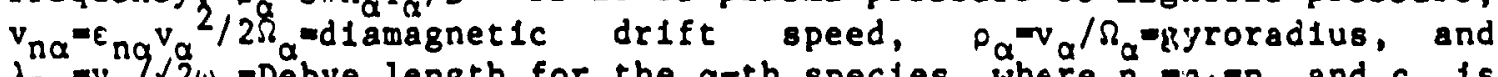

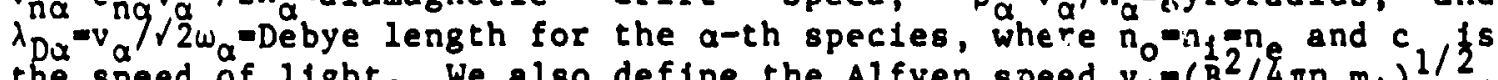
the speed of 11ght. We also defing the Alfven speed $v_{A}=\left(B^{2} / 4 \pi n_{0} m_{1}\right)^{1 / 2}$, the sound speed $f_{s}=\left(\left(T_{e}+3 T_{1}\right) / w_{1}\right) 1 / 2$ and the lower hybrid frequency $\omega_{L H} \omega_{1} /\left(1+\omega_{e} / \Omega_{e}{ }^{2} \rho_{1}\right.$. In the analysis of the various Instablleles we assume the magnetic field $B$ is in the $z$ direction, gradients in the densities $\left(\varepsilon_{n \alpha}=\nabla n_{\alpha} / n_{\alpha}\right)$, temperatures $\left(\varepsilon_{T a}=\nabla T_{\alpha} / T_{\alpha}\right)$ and magnetic fleld $\left(\varepsilon_{B}=\nabla B / B\right)$ lie along $x$ and the relative electron-ion ift $v_{-}$is along $y$. For shocks, the flow speed normal to the shock $18 V_{x}$ and the Alfven Mach number $18 \mathrm{M}_{A}=V_{x} / v_{A}$. For the local linear analysis we toke the wavevector $k$ to lie in the $y-z$ plane, $k-k_{y} y+k_{z} z$, with $\theta=\cos ^{-1}\left(k_{z} / k\right)$, and assume perturbatlons grow as exp( $1(k \cdot x-\omega t)) w 1 t h w=\omega_{r}+1 \gamma$.

We next recall the basic geometry of a quasiperpendlcular shock, as shown in $\mathrm{HIg}$. 1. (Figure and discussion is after Wu (1982).) The solid curve deplcts the magnitude of the wagnetic field ns well as density and temperature of the various components. To the lett is the upstreaw atse with plasma flowing to the right into the shocked reglon; to the right is the downstream state, howing the rise in these quantities across the tranaition layer. According to the old 1dea that the shock evolves from a magnetosonic soliton due to diselpation (Tidwan and Kral1, Chapter 3, 1971), the width of this layer 18 an lectron Inertial length, $c / w_{e}$. Because the width 1s comparabie $\left(B_{e}^{-1}\right)$ to an electron gyrcradius, the electron orbits are aignificantly modifled as they enter the chock. The lons, on the other hand, pass through the transition reglon very rapidly and are eseentially unmagnetized. The difference in the electron and ion behavior leads to - charge eeparation, resulting in an electric fleld, Ex. The electrons thue experience on ExB drift acrose the magnetic field, which gives 
rise to a cross-field current (which must be there self-consisteitly to provide the Increase in the magnetic fleld dictated by Ampere's $1 a w)$. Besides the ExB electron drift, the gradients in the densities, temperatures and magnetic field result in additional cross-field drifts. If the shock is not perpendicular, the same arguments hold with the addition of a component of the electric field parallel to the magnetic field. For high Mach number shocks not all the lons are transwitt.'d through the shock; rather, some are reflected at the shock frunt and then, depending on the geometry, return upstream or gyrate downstream.

A relative electron-ion drift can generate varlous plasma instabilities. These instabilities imply the growth of plasma waves which may be oscillations in the electric field alone (1.e., electrostatic" fluctuations) or in the magnetic field as well (electromagnetic fluctuations). Generally, such waves grow to some level where they begin to interact back on the particles, giving rise to a frlctional force that leads to plasma heating and resistivity. It is the purpose of this review to $g$ ive the uninitiated reader a feeling of how this can occur as well as references where the detalls of the theory can be found and to give the more informed reader a summary of the present status of the fleld.

B. Evidence for turbulent heating

Before proceding to a detailed discussion of kow to calculate plasma heating due to instabllities, we pause to ask whether such heating is really very lmportant to shocks by considering several examples. The first example is a low Mach number, larninar quasiperpendicular shock. Figure 2 shows the evolution of various macroscopic quantities for the shock crossing of August 27, 1978 (Thomsen et al., 1984). The density and magnet1c fleld (not shown) both increase about a factor of two across the shock. The electron temperature also Increases by the same amount, consistent with compressional heating, while the lon temperature increases much more, about a factor of ten across the shock. The second example is a supercritical, nearly perpendlcular shock from Nov. 7, 1977. The macroscopic quantities displayed in Fig. 3 (from Sckopke et al., 1983) again show modest increases across the shock, except for the Ion temperature. In this case Ion reflection provides the dissipation needed to form the shock (see revlews by Goodrich and Robson). In the downstream region, however, these reflected lons add to a vary large kinctic temperature, whlch eventually becomes thermalized (again through an Instablitty to be discussed later), but with a persisting non-Maxwellian shoulder.

Cenerally, at many of these shocks the overall electron temperature is not increased very much above its adiabatic value; however, ti:e effect of instabilities on the electrons 18 not indignificant. The evolution of the electron distribution function across the transition layer for the quasiperpendicular shock of December 13, 1977 is shown in F18. 4 (Feldman et al., 1983). In this case, which 18 typlcal of many crossings, the electron distribution becomes flattopped in the downetream region, indicating there are mlcroscopic wave-particle interactions occurring. (See review by Feldman.) 
Evidence for turbulent heating also comes from the wave measurements. Figure 5 (from Wu et al., 1984) shows the evolution of the electric field fluctuation spectrum during the shock crossing of November 7, 197\%. As the spacecraft passes through the narrow transition layer, the electric nolse increases by many orders of magnitude in the frequency range 100-1000 $\mathrm{Hz}$. Th1s feature is characteristic of bow shock spectra and is discussed in detall in Rodriguez and Gurnett (1975) and Gurnett's review.

C. Quasilinear transport coefficients

To show how Instabilities enter Into transport considerations, we derive a set of moment equations for the macroscoplc quantities of interest. (For more complete discussions refer to: Davidson and Krall, 1977; Gary, 1980.) We start with the Vlasov equation for the $\alpha-t h$ species

$\frac{\partial f_{\alpha}}{\partial t}+\underline{v} \cdot \frac{\partial f_{\alpha}}{\partial \underline{x}}+\frac{e_{\alpha}}{m_{\alpha}}\left(\underline{z}+\frac{\underline{v} \times \underline{B}}{c}\right) \cdot \frac{\partial f_{\alpha}}{\partial \underline{v}}=0$

and subdivide quantities into slowly varying (on the time scale of approprlate Instablities) (denoted by $-:$ and rapidly varying (denoted by $\sim$ )

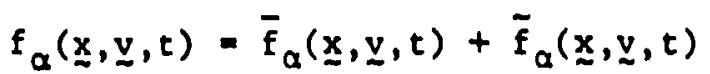

$B(\underline{x}, \underline{v}, t)=\vec{B}(\underline{x}, t)+\underset{\vec{B}}{\tilde{B}}(\underline{x}, t)$

$\underline{E}(\underline{x}, t)=\bar{E}(\underline{x}, t)+\underset{E}{E}(\underline{x}, t)$

with $\bar{E}$ and $\bar{B}$ the equilibrium electric and magnetic flelds, respectively. Upon Inserting these expressions into Eq. (2) and performing an ensemble average (denoted by $\langle$ ), we obtain an equation for the slowly varying part of the distribution function:

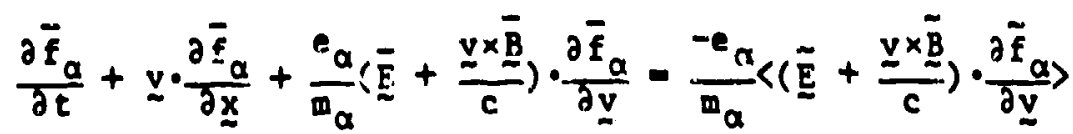

The right hand side acts as a collision term giving rise to exchange of 
momentum and energy between the various plasma specles and the waves. Varlous velocity moments can be defined:

$\bar{n}_{\alpha}=\int \bar{f}_{\alpha} d \underline{v}$

$\overline{\mathbf{I}}_{\alpha}=\overline{\mathbf{n}}_{\alpha} \overline{\mathbf{v}}_{\alpha}=\int \bar{f}_{\alpha} \mathbf{v d v}$

$\overline{\mathbf{w}}_{\alpha}-\int \overline{\mathbf{f}}_{\alpha \underline{\text { vod }} \mathbf{v}}$

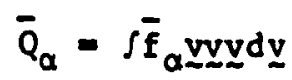

(with similar moments for $\bar{f}$ ) and moment equations can then be obtalned by multiplying Eq. (3) by various components of $\underline{v}$ and integrating:

$\frac{\partial \bar{n}_{\alpha}}{\partial t}+\frac{\partial}{\partial \underline{x}} \cdot \bar{I}_{\alpha}=0$

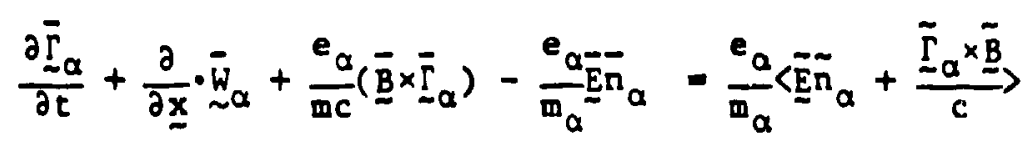

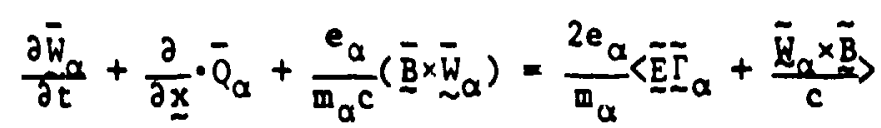

supplenented by Maxwell's equations:

$\underset{\nabla}{\nabla} \cdot \bar{z}-4 \pi \sum_{a} e_{a} \bar{n}_{a}$

$\nabla \times \bar{B}=\frac{4 \pi}{c_{\alpha}} \sum_{\alpha} \overline{\bar{I}}_{\alpha}+\frac{1 \partial \bar{E}}{c \partial t}$ 
$\underset{\nabla}{\nabla} \bar{\sim}=-\frac{1 \partial \bar{B}}{c \partial t}$

$\underset{\nabla}{\bar{B}}=0$

The system is a rather formidable one to solve. To see the essentlal featuren, assume a homogeneous system $(\partial / \partial x-0)$, take f $a$ to be an sutropic Maxwellian with a net drift and sum the equation for $W_{\alpha}($ Eq.
yleld:

$\frac{\partial \overline{\underline{V}}_{\alpha}}{\partial t}+\frac{e_{\alpha}}{m_{\alpha} c}\left(\bar{B}^{\prime} \times \bar{V}_{\alpha}\right)=\frac{e_{\alpha}}{n_{\alpha} m_{\alpha}}\left\langle\tilde{\tilde{E}}_{\alpha}+\frac{\tilde{I}_{\alpha} \times \tilde{B}}{c}\right\rangle$

$\frac{\partial T_{\alpha}}{\partial t}=\frac{2 e_{\alpha}}{3 n_{\alpha}}\left\langle\tilde{\tilde{E}} \cdot \tilde{\Gamma}_{\alpha}-\overline{\mathrm{V}}_{\alpha} \cdot \tilde{\mathrm{E}}_{\sim} \tilde{n}_{\alpha}\right.$

We then define the resistivity (Davidson and Krall, 1277)

$v=4 \pi v^{\star} / \omega_{e}^{2}$

in terms of the collision frequency

$v^{\star}=\frac{-e\left\langle\tilde{E}_{e}+\tilde{I}_{e} \times \tilde{B} / c\right\rangle \cdot v_{d}}{n_{e} \tilde{m}^{v_{d}}{ }^{2}}$

and the heat ing frequencles

${ }_{T \alpha}=\frac{2 e_{\alpha}}{3 n_{\alpha} T_{\alpha}}\left\langle\tilde{E} \cdot \tilde{I}_{\alpha}-{\overline{Z_{\alpha}}}_{\alpha} \cdot \tilde{E}_{\alpha}\right\rangle$ 
In this form it is evident that the heating and collision frequencies come from a coherent interaction of the particles with the fluctuating fields. We will show later how to evaluate such expressions.

D. Prescription for calculating dissipation

The prescription for computing the turbulent dissipation consists of the following four steps. A sore detalled fustification of the assumptions made in each step is found in Davidson and Rrall (1977) and Gary (1980).

Step 1: Identify the instabilities. This 1nvolves first locating the sources of free energy, such as particle drifts, gradients in density, temperature, magnetic fleld, non-Maxwellian velocity distributions (e.g., anisotroples, loss cones, etc.). In a shock such sources may be function of position, e.g., strong gradients and drifts in the ramp region, reflected lons in the foot, etc. (see Wu et al., 1984). Further, one has to decide on the frequency range of Interest (Hre the lons magnetized or not) and the type of wave (electrostrtic or electromagnetic) to look for.

Step 2: Solve the appropriate l1near dispersion equation. In

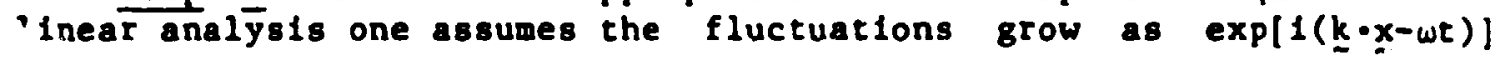
w- $\omega^{-1}+1 \gamma$ ). (In assuming such a Fourler representation we tacitly Ignore spatial dependences; hence, the calculation is a local one, at a particular position in the shock,) For electrostatic perturbations one then solves Poisson's equation, relating the perturbed electric field (expressed in terms of a potential) to the persurbed charge density:

$\nabla \cdot \bar{E}=1 \underline{k} \cdot(-1 \underline{k} \bar{\phi})=4 \pi \sum_{\alpha} e_{\alpha} \tilde{n}_{\alpha}$.

Since (as shown below) $n_{\alpha}$ can be related to

$\tilde{n}_{a}=x_{a} \tilde{\sigma}$

one obtains

$k^{2-}=4 \pi \sum_{\alpha} e_{\alpha} x_{\alpha} \tilde{\phi}$.

or diaperaion equation

$k^{2}-4 \pi \sum_{a} e_{a} x_{a}=0$

relating $w$ and $k$ with properties of the plasas. 
The perturbed charge density is obtalned by iniegrating the perturbed distribution $\overline{\mathrm{f}}_{\alpha}$ over velocity (Eq. (4)). $\tilde{\mathrm{f}}_{\alpha}$ ls obtained from the linearized vlasov equation:

$\frac{\partial \tilde{f}_{\alpha}}{\partial t}+\underline{v} \cdot \frac{\partial \tilde{f}_{a}}{\partial \underline{x}}+\frac{e_{\alpha}}{m_{\alpha}}\left(\underline{\bar{E}}+\frac{\underline{v} \times \bar{B}}{c}\right) \cdot \frac{\partial \bar{f}_{\alpha}}{\partial \underline{v}}=0$

which can be solved by the method of characteristics (Krall and Trivelplece, Chaprer 8, 1973)

$\left.\tilde{f}_{\alpha}=\frac{e_{\alpha}}{w_{\alpha}} d t^{-} \exp \left\{1 \underline{k} \cdot\left(\underline{x}^{-}-\underline{x}\right)-w\left(t^{-}-t\right)\right\}\right]\left(\underline{\tilde{E}}+\frac{\underline{v}^{-} \times \underline{\bar{B}}}{c}\right) \cdot \frac{\partial \bar{f}_{\alpha}}{\partial \underline{q}^{-}}$

long the orbit $\underline{x}^{-}\left(t^{-}\right), \underline{v}^{-}\left(t^{-}\right)$such that $\underline{x}^{-}(t)=\underline{x}$ and $\underline{v}^{-}(t)=\underline{v}$. In general, this can be a cowplicated tuolness, especially when grädients are lacluded.

For electromagnetic perturbations the same procedure is followed, except now one solves the other Maxwell's equations as well:

$\nabla \times \bar{E}=-\frac{1 \partial \tilde{B}}{c \partial t}$

$\nabla \times \underline{B}=\frac{4 \pi \tilde{j}}{c}+\frac{1 \partial \vec{E}}{c \partial t}$

$\nabla \cdot \underline{\tilde{B}}=0$

where

$\tilde{I}=\Sigma e_{a} \bar{I}_{c}=0 \cdot \tilde{E}$.

These equations reduce to: 
$\underline{\underline{k}} \times(\underline{k} \times \overline{\tilde{E}})+\frac{\omega^{2}}{c^{2}} \bar{E}+\frac{4 \pi 1 \omega}{c^{2}}-0 \cdot \tilde{E}=D \cdot \underline{\tilde{E}}$

and thus the dispersion equation 18

Det $|D|=0$.

In addition to being necessary for computing the dissipation, the linear analysis reveals under what conditions the instability exists $(\gamma>0)$ and how its characteristics vary with the parameters of the system. Indeed, most of the work on Instabllity theory for shocks (as well as elsewhere) is concerned with such local, linear analysis.

Step 3: Estimate the fluctuation level. In the evaluation of the resistivity or the heating rates (Eqs.( $(8-10)$ ), quantitles like $\left\langle\bar{E} \cdot \bar{I}_{a}\right\rangle$ and $\left\langle\underline{E} \tilde{n}_{a}\right\rangle$ have to be eviluated. From linear theory relations between $\bar{I}_{a}$ or $\bar{n}_{a}$ and $\underline{E}$ can be obtained (Eqs. (12) and (18)) and the ensemble averages can then be evaluated

$\left\langle\bar{E}_{1} \bar{n}_{\alpha}\right\rangle=\left\langle\sum_{j} \bar{E}_{1} x_{\alpha} \bar{E}_{j}\right\rangle=\left\langle\sum_{j}\left(\sum_{k, \omega} \bar{E}_{i}(k, \omega)\right)\left(\sum_{k, \omega}^{\sum} \bar{E}_{j}\left(k^{-}, \omega^{-}\right) x_{\alpha}\left(k^{-}, \omega^{-}\right)\right)\right\rangle$

The easemble averages imply that only waves in phase contribute (1.e., Raniow Phase Approximatior),

$\left\langle\tilde{E}_{1} \tilde{n}_{a}\right\rangle=\sum_{k, \omega}\left|E_{1}(k, \omega)\right|^{2} x_{a}(k, \omega)$

The quant1ty, $|E(k, \omega)| / 8 \pi-\varepsilon_{k}$, is the energy dens1:y in one particular mode. According to linear theory, if an instability exists, the unstable waves grow exponentially; but growth eventually ceases at sowe finite level and the task is to deteralne $c_{k}$ when this occurs. There are varlous bays to do this, whlch way vary frow instabllity to Instabllity, some of which will be described in the next section.

One rather easy aethod to get an upper bound on the fluctuation level which is comonily used is to assune that all of the free energy 1s converted to fluctuations. This of ten gives the correct ecaling of the aturation level with accroscroplc parameters, although it can overestlaate the fluctuation level by quite a blt, depending on how auch of the free energy goes Into heating of the plasma Instead and how wuct free energy reasins when the instabllity 1s stabllized. The procedure is usually olaplifled further by anuming all the wave energy resides in one mode, typlcally the one nost unstable according to IInear theory. It should be polnted out, however, that thls wethod 
does not necessar1ly work well for the shock, where a stat lonary state is reached by balancing the rate of growth of the instability with the rate of diselpation, rather than by relaxing the free energy to achieve a marginally stable state.

A common alternative method for obtalning the fluctuation level is to run some sort of computer simulation of the 1nstability. This is a very useful technique, which allows at the eame tiae the opyortunity to verlfy linear tineoly and measure hesting rates as well. Again, the boundary conditions which are often lwposed to atudy the instablilties in idealized situations are not always approprlate to conditions in the shock. Such simulations are valuable nevertheless, and some examples will be given it the next section. Interested rtaders are urged ro read Vols. 9 end 16 of Methods of Computational. Physics (Academic Press) and the forthcoming book on simulation methods for space plasmas by H. Matsumoto and T. Sar.o (D. Reidel, 1984).

Step 4: Solve the transport equations. Generally, the full set of equations $(5-6)$ is too difficult to solve and so approximations to reduce them to just expressions for the heating rates and resistivity $(8-10)$ are made. Even in this simplified form the results are useful and expressions for the varlous lintabilities have been collecred together. For example, Llewer and Krall (1973) have obtained expressions for the instabilities relevant to perpendiculaz shocks. Lampe et al. (1975) have a more inclusive set for hydrodynamic instablities. Davidson and Krall (1977) have collected the transport cnefficients needed to model theta-pinch experiments. Gary (1980) has put together a complete formalism for electrostatic, cross-field instabilities, whose nonlinear behavior has been treated in a consistent fashion. Trarsport coefficients can ba derived in a much more elegant manner as well (Dum, 1978a and 1978b), as will be shown later.

It Is also prssible to solve the time-dependent iranspor: equations numerically, with the anomalous terms evaluated locally in space and time (e.g., see Davidson and Krall (1977) and review by Papadopoulos, this meeting;. This technique has been successfully employed in analyzing theta-pinch experiments (Hamasaki et $21 ., 1977$ ), although the level of agreement between calculation and experimental weasurements is no better than when slapiffled phenomenologiral expressions for the transport coefficlents (Sgro, 1978) are used. Such calculations are generally complicated and to extend them to oblique geometries becomes even more of a problem because ti - nonlinear character of the varlous cross-field instabilities is then somewhat uncertain and other alssipution processes come into play.

\section{Instailities}

prescription described in the previous section to collisionless shocks. After identifying which mocies are thought to be the most Important we cxamine each in turn and summarize the current knowledge about their linear, nonlinea:, and transport properties, particularly in regard to shocks.

\section{A. Classiflcation}

To Ident!fy the Inatabllities we refer back to Fig. 1 to recall the sources of free energy. For quasiperpendicular shocks the principal source of free energy is the cross-field current, $1 . e .$, the 
relative electron-1ion drift across the magnetic field due to the $E \times B$ drift, the $\nabla B$ drift, and diamagnetic drifts due to density and temperature gradients. There can also be relative electron-ion drifts along the magnetic field. Furtherwore, the conservation of the magnetic moment of the electrons and increase of the magnetic field at the shock produres a temperature anlsotropy, $\mathrm{T}_{e \perp} / \mathrm{T}_{\mathrm{e}}>1$. For supercritical shocks ion reflection occurs, wh1ch leads to relative electron-ion drifts in the foot region and a large energy anisotropy, $E_{\perp} / E_{1}$, downstream of the wain shock transition. The reflection process generates a large: sunt of free energy in the reflected ion component that can have a very significant effect on the various microinstablifties at the shock, as emphasized by wu et al. (1984).

Following the observations (Rodr:guez and Gurnett, 1975 and 1976; Wu et al., 1984; Gurnett review th1s meeting), we subdivici the instabilities into high frequency waves that sre electrostatic and low frequency modes which have a strong electromagnetic component. The high frequency modes to be discussed include the ion rcoustic Instability (with a littl, about the hydrodynamic limit--the Buneman Instability--included) and the electron cyclotron drift instability. The low frequency modes include the lon-ion instablifty, the modified two stream (also kncwn as the kinetic cross-field streaming) Instability, and the lower hybrid dift instablity. For the most part we consider each of these modes as isolated cases; fet papers compare the various instabilities under similar conditiors, especially for shocks. There are two notable exceptions (Lashmore-Davies and Martin, 1973; Lemuns and Gary, 1978), which provide valuable insight to the interconnection of the varicus modes.

There are, of course, many other instabilities as well. Waves at or below the ion cyclotron frequency (including most drift waves) dre gererally ignored, because the time scales for these waves to transverse the shock is too short for them to grow to appreciabie levels. Other modes hich could contribiste will be discussed only very briefly, elther because they have been treated in only a limited manner (e.g., Ion velocity ring modes, Wu et al., 1984), or they are being considered in other reviews at this meeting (e.g., parametric decay Instabilities at quasiparallel shocks by Quest, beam-ilke Ion acoustic modes by Feldman, electron whistlers by Gurnett, and the electromagnetic ion cyclotron instability which iiclmalizes reflected lons by Goodrich).

\section{B. High frequency instabilities}

1. Ior acoustlc instablilty

The 10n acoustic instability has been the most often invoked process for explaining turbulent heating and resistivity in shocks. Its linear propertles are well known (e.8., Krall and Trivelplece, Chapter 8, 1973). The Ion ocoustic Instablitty 18 an electrostatic mode driven by relative electron-ion drif:s along or across a magnetic field. The instablitty is driven by a resonant interaction with the electrons $\left[\left(\omega-k v_{d}\right) / k_{\|} v_{e}\left\langle\langle 1]\right.\right.$ while the lons are nonresonant $\left.\left.\left(\omega / k v_{f}\right)\right\rangle 1\right)$. More importantly, there 18 a threshold condition for instablitity, $v_{d}>c_{g}$. When $T_{1}=T_{e}$ the threshold is very $h$ igh, $v_{d}>v_{e}$, and the lnstability becomes fluld-1ike rather than kinetic and is usually referred to in this limit as the Buneman instablilty. (Because the threshold 18 so high, Implying a current layer thickness $\mathrm{rc} / \mathrm{w}_{e}\left(\mathrm{~B}_{\mathrm{e}} \mathrm{\alpha l}\right)$, it 18 less interesting for shock applications.) In the case of a 
cross-fleld current (with $\mathfrak{f}$ along $y$ and $B$ along 2 ) for $\underline{k}$ not parallel to $f\left(1 . e ., k=k_{y} y+k_{z} z\right.$ ) the linear dispersion equation reduces to that of the $(B=0)$ Ion acoustic made. As $k_{2}$ goes to zero, the resonant nature of the electrons 18 lost and the 1nstablil:y goes over to the electron cyclotron drift instablitty, to be fiscussed later.

The linear properties of the lon asoustic mode are given by (for maximus growth):

$$
\begin{aligned}
& \omega_{\tau}=k c_{s}\left(1+k^{2} \lambda_{D e}{ }^{2}\right)^{-1 / 2} \\
& \gamma=\left(\frac{\pi}{8}\right)^{1 / 2} \frac{\left|\omega_{r}\right|}{\left(1+k^{2} \lambda_{D E}{ }^{2}\right)^{3 / 2}}\left(\frac{m_{e}}{m_{i}}\right)^{1 / 2}\left(\frac{k \cdot v_{d}}{\omega_{I}}-1\right)-\left(\frac{T_{e}}{T_{1}}\right)^{3 / 2} \exp \left[\frac{-T_{e}}{2 T_{1}\left(1+k^{2} \lambda_{D E}{ }^{2}\right)}\right]
\end{aligned}
$$

or in the 1 imlt $v_{e}>v_{d}>c_{s}$

$w_{r}=w_{1} / \sqrt{ } 3$

$k=\left(2 \lambda_{D e}\right)^{-1 / 2}$

$r=\frac{1}{3}\left(\frac{\pi m_{e}}{6 m_{1}}\right) 1 / 2 \frac{v_{d}}{c_{s}} \omega_{1}$

while those of the Buneman instability gre:

$$
\begin{aligned}
& \omega_{r}=\frac{1}{2}\left(\frac{w_{e}}{2 \sigma_{1}}\right)^{1 / 3} \omega_{e} \\
& r=\sqrt{3} \omega_{r} \\
& k=\omega_{e} / v_{d} .
\end{aligned}
$$

For shock geometries the threshold condition for the lon acoustic lnstablitty (which to roughly $\left(v_{d} / v_{e}\right)\left(T_{e} / T_{1}\right)>1$ ) can he raduced by 
gradients in the density and electron temperature (Priest and Sanderson, 1972; Soldner et al., 1977). The gradients distort the electron distribution function, Increasing 1 ts derivative at $\mathrm{v}=\mathrm{w} / \mathrm{k}$. In high Mach number quasiperpendicular shocks distortions in the ion distribution function caused by the presence of reflected lons can similarly lower the threshold for the instablitty by reducing the ion Landau damping (Wu et al., 1984).

The understanding of the nonlinear behavior of the lon acoustic Instability has not advanced much in recent years, so that pepadopoulos (1977) remains an excellent summary. In the case of a cross-field current the magnetic fleld prevents electron runaway and keeps the electron velocity distribution 1sotropic. Saturation of the Instability is then due to nonlinear lon dynamics, which have been described in"several ways. In the weak turbulnnce approach (Kadonsev, 1965; Sagdeev and Galeev, 1969) 11near growth is balanced by nonlinear Landau damping to give a saturation level

$W=\frac{|E|^{2}}{8 \pi n T_{e}}=10^{-2} \frac{v_{d}}{v_{e}} \frac{T_{e}}{T_{1}}$,

a spectrum for the fluctuations

$|\gamma|^{2} \sim \frac{2}{k^{3}} \ln \frac{1}{k \lambda D e}$

a collision frequency

$$
v^{\star} \approx 10^{-2} \frac{T_{e}}{T_{1}} \frac{v_{d}}{v_{e}} w_{e},
$$

and a seath width

$\Delta \sim 10^{-1}\left(\frac{w_{e}}{\Omega_{e}}\right)^{1 / 3}\left(\frac{m_{1}}{m_{e}}\right)^{1 / 3} \beta_{e}-2 / 3 \mathrm{c} / \omega_{e}$.

Galeev (1976) glves another derivation, finding 
$\Delta \sim\left(\frac{m_{e}}{m_{1}}\right)^{1 / 4} B_{e}^{-1 / 2}\left(M_{A}^{2}-1\right) \quad c / \omega_{1}$.

Horton et al. (1976) have redone the weak turbulence theory more carefully (removing some of the numerical divergences) and solved the resulting time-dependent mode coupling equations for the turbulent spectrum. Scaling laws based on this renormalized theory have also been obtulned (Horton et al., 1979).

In another spproach (sleeper et al, 1973; Wesson and Sykes, 1973) the linear growth of the waves 18 balanced by a broadening of the 1 in Landau resonance due to the perturbation of the lon orbits by the turbulance. The result is a complicated set of equations for the angular spectrum which can be solved numerically. A third approach ('Tystovich, 1972) 1s based on a kinetic wave equation which 1acludes a nonlinear broadening of the decay condition.

The nonlinear theorles also give values for the resistivity (e.g.,

weak turbulence result above). Gary (1980) has computed the resistivity and heating rates assuming the saturation level is determl ied by lon trapping (B1skamp and Chodura, 1971). Dum (1978a) has derived the transport coefficients for the 1on acoustic instabllity in a more elegant fashion, by consicering a kinetic equation which includes collisions due to Coulomb interactions as well as turbulence. The electron distribution, derived self-consistently, is flattopped (e.g., F1g. 4), f $\epsilon^{-} \exp \left[-\left(|v| / v_{e}\right)^{-s}\right]\left(s^{-4-6)}\right.$. The transport consistent with this distribution (resistivity and heating) is significantly modifled from that obtained with a simple Maxwellian (s=2) distribution. In a second paper (Dum, 1978b) the theory 18 extended to include gradients and a parallel current.

The nonlinear theorles have been supported by simulation studies (Morse and N1elson, 1971; Biskamp and Chodura, 1971), the most realistic of which are the two-dimensional calculations of Dum et al. (1974) with a current (that was kept constant) across a weak magnetic fleld. Instead of forming atationary state, the fluctuations grow, saturate, and then relax, eventually returning tu near thermal levels. The electrons are slightly heated and form a flattopped distribution, while high energy ion "talls" are formed, instead of bulk lon heating.

The ion acoustic Instability is almost always proposed to explain the observed electrostatic vaves at the bow shock (Rodriguez and Gurnett, 1975 and 1976), although there have been no dlrect measurements of the wavelengths aid little theoretical analyois. Evidence for its existence enters indirectly, by the observation of Elattopped electron distributions (Feldman et al., 1983) and through the use of a marginul stability condition to explain the width of quasiperpendicular, laminar sincks (Morse and Greenstadt, 1976; Greenotudt et $1 ., 1978$ ). The shock widthth, $\Delta$, is desermined from Ampere" 1aw with the value of the current such that the fon acoustic Instablity relaxes to 1 ts marginal stablilty condition, $v_{d}{ }^{*}-c_{s} f\left(T_{e} / T_{1}\right)$ (Manheimer and Bor1s, 1972): 
$\Delta=\frac{\Delta B}{B} \frac{1}{B_{e}^{1 / 2}} \frac{1}{\xi} \frac{C}{\omega_{1}}$.

On the other hand, more recent data from ISEE-1 and 2 (Russell et al, 1982) suggest that the shock width 18 better fit by the weak turbulence condition (30), or simply $\mathrm{c} / \mathrm{w}_{f}$, rather than the marginal stabllity condition. However, Russell et al. do not explain how the shocks they observe can be too broad to satisfy the Ion ucoustic condition, yet be well described by a theory based on lon acoutlc turbulence.

For the Ion acoustic 1sstablitty to be effective, and not require steep gradients, $\left.T_{e} / T_{1}\right\rangle 1$ is needed. Th1s condition is not always met, however. In some cases (see Blskamp, 1973) there are sugsestions that the leading edge of the shock can steepen up so that $v_{d}>v_{e}$, triggering the Buneman Instablifty. When this occurs, the electrons are strongly heated, as seen in both simulacions in both one (Morse and Nielson, 1971; Davidson et $\mathrm{al} ., 1971$ ) and two (Lampe et al, 1974; Dum and Choura, 1979) dimensions, so that the usual Ion acoustic instablitty can then operate throughout the rost of the shock. This preheating does not always occur (e.8., the bow shock); sometlmes $T_{e} / T_{1}<1$ persists and another instability mechanism, the electron cyclotron drit instability, is needed.

\section{Electron cyclotron drift instability}

This instability exists in a small region of $k$-space near $k_{z}=0$ (for $\$$ along $y$ and $B$ along $z$ ) and results from the couping of a Dopplex shifted Bernstein wave and an Ion wave. (See Lashmore-Davies and Martin, 1973).) For $T_{e} / T_{1}>1$, 1t 18 a fluid Instability and becomes 101. -acoustic-11ke for $k_{2} \neq 0$. Its domaln of Instability $\left(k_{z} / k\right)$ Increases with $v_{d} / v_{e}$. Most importantly, the instability persists for $T_{e} / T_{1}<1$, becoming kinetic in noture. For $k_{y} \rho_{e} \gg 1$, 1ts linear properties are given by (Lashmore-Davies and Martin, 1973)

$\omega_{r}-k_{y} v_{d}-n \Omega_{e}$

$\gamma=\Omega_{e} \frac{n^{1 / 2}}{(B \pi)^{1 / 4}}\left(\frac{m_{e}}{m_{1}}\right)^{1 / 4}\left(1+k^{2} \lambda_{D e}{ }^{2}\right)^{-3 / 4}$

$k_{y} v_{d}=n \Omega_{e}+k c_{B}\left(1+k^{2} \lambda_{D e}{ }^{2}\right)^{-3 / 4}$

The extstence of th1s mode for shocke has been debated. Equation (32) ousgeats 1t. woula be found in (Doppler shifted) bands around $n_{0}$. (Note that bncause $w_{e}>\Omega_{e}$ at the shock, $\Omega_{e}^{-} w_{1}$, so that 18 difficult to dietinguish this mode from the ion acoustic.) Wu and rredricke (1972) argue. that che narrow band aplkes of electrostatic nolse obeerved by 0GO-5 were ignatures of the Instablilty, although such features were 
not found in more recent IMP-6 (Rodriguez and Gurnett, 1975) and ISEE data (Greenstadt et al., 1980). It has been recently shown by 2 hou et al. (1984) that magnetic fleld gradients stabilize the Instability for perpendicular shocks, perhaps suggesting why it 1s not often observed. Another reason why it 18 not usually seen may be because the instability saturates at low levels (Lampe et al., 1972a). Since the Instability involves undamped Berstein waves, any perturbation of the electron orbits is a stabilizing effect. Based on th1s 1dea, $1 \mathrm{t}$ is easy to estimate the saturation level assuming the limiting level of turbulence is such that a particle diffuses half a wavelength in one 8yroperiod (B1skamp and Chodura, 1973):

$D \approx \frac{(\Delta x)^{2}}{\Delta t}=\frac{1}{2} \pi \frac{\Omega_{e}}{k^{2}}$.

Using a siople Fokker-Planck diffusion model, D can be approxingted as

$D=(2 \pi)^{1 / 2} \frac{\omega_{e}^{2}}{\Omega_{e}{ }^{2}} \frac{|\tilde{E}|^{2}}{8 \pi n T e} \frac{v_{e}}{\langle k\rangle}$.

Combining these two results ylelds the saturation level:

$W=\frac{|E|^{2}}{8 \pi \pi T_{e}}=\left(\frac{\pi}{8}\right)^{1 / 2} \frac{\Omega_{t}^{2}}{\omega_{e}{ }^{2}} \frac{\Omega_{e}}{k v_{e}} \frac{\langle k\rangle}{k}$.

Since $k v_{e}{ }^{-\omega_{e}}$ and $\omega_{e} \gg \Omega_{e}, W$ is very omall. That would be the end of the - tory, except that computer simulations (which origlnally showed the potency of the instablitey (Forslund et al., 1970)) revealed that a nonilnear electron cyclotron Inytablitty 15 . Tso exclted (Forslund et a1., 1971; Lampe et al., 19\%; Biskamp and Chodura, 1972). ThTs nonlinear inetablitey cannot be described by a dispersion equation and one has to rely on computer simulation for Insight.

The nonlinear evolution of the instability in part depends on how the sinulations are conducted. In one-ilmensional calculations the 1nstabllity otrongly heats electrons and lons and sugsests a cohorent process oscurs. In th1s case the heating rate veconstant and phase -pase pictures indicate that the electrons continuously become trapped and then untrapped by the magnetic fleld. When $v_{e}$ increases so that $v_{d}$ (kept constant) $\times v_{e}\left(\Omega_{e} / w_{e}\right)$ the inatablilty awitches - $f f$. The condition 
for starting the Instabllity looks very wuch like the lon acoustic cond1tion $\left(\left(v_{d} / v_{e}\right)\left(T_{e} / T_{1}\right)>1 / 2\right)$ (Lampe et al, 1972b), but this can be reduced by the presence of turbulence (Biakamp and Chodura, 1973). In two dimensions the Instability is wuch weaker and the electron heating 18 more stochastic. It has been studied only in the case $T_{e} \gg T_{1}$, where 1t looks like the unmagnetized Ion acoustic 1nstability.

Finally, it should be mentioned that in high Mach number quasiperpendicular shocks reflected lons can also drive the electron cyclotron drift 1nstability (11nearly) in the direction of the shock normal. This has been observed in a theta-pinch experiment (Gold et al., 1980) and may explain some of the h1gh frequensy nolse observed $\overline{a t}$ the shock. Whether it has (or 1s) a nonlinear analogue is not known at present.

\section{Low frequency instablities}

1. Ion-1on Instability

Like the electron cyclotroi: drift instabllity the 1on-1on instability was investigated extensively a decade ago and little has been done since. An excellent discussion of 1 ts propertles is found in Biskamp (1973). The linear theory is derived most: simply in the case of two equal density beams, counterstreaming $\left( \pm v_{d}\right)$ perpendicular to the wagnetic fleld. Assuming strongly magnetized electrons $\left(\omega<\left\langle\Omega_{e}\right)\right.$ and unmagnetized lons $\left(\omega \gg>\Omega_{f}\right)$ the maximum growth rate and corresponding wavenumber are (Papadopoulos et al., 1971):

$\gamma=\omega_{L H} / / 8$

$k=\sqrt{3 y} / v_{d} \quad .(36)$

For unequal beams the dispersion equation has to be solved numerically; $\omega_{r}$ and $\gamma$ lie in the lower hybrid frequency range. For finite $B_{e}$ the Instability stabilizes when

$v_{d} \cos \alpha i v_{A}\left(1+\beta_{e}\right)^{1 / 2}$,

where $k \cdot y_{d}=k v_{d} \cos \alpha$. For modes propagating parallel to the beat diriction then stablility occurs when the beam speed is roughly the Alfuen speed; the condition (37), however, tates that for any $v$, there will always be some off-angle modes which are unstable (with somawhat smaller growth rates). Kinetic corrections to the linear diaperaton equation have been discussed by Auer et al. (1971) and recently reexamlned by Wu et al. (1984). These calculations show, for example, that for fixed $\bar{B}_{1}$, the inatability is enhanced by increasing $B_{\mathbf{e}}$. 
One-diluensional simulations (Papadopoulos et al, 1971) demonstrate that the 1 astabilicy leads to otrong lon heat $1 n_{g}$ (trapplng) for $v_{d}<v_{A}$ and the hearing process can be described by aet of quasilinear rate equations. Later calculations verifled that finlte beta stabilization occurs for $v_{d}>v_{A}$ (Wagner et al., 1971). This has been shown more clearly in recent two-dimensional calculations by Lee et al. (1981). In cases where the parallel (cos $a=1$ ) modes are stable, the oblique modes still. grcw, but no strong lon heacing occurs.

It was originelly thought that the Ion-1on instabllity would occur between the solar wind lons and the reflected lons in supercritical quasiperpendicular shocks, leacing to the observed strong ion heating (Auer et al, 197:; Papadopoulos, 1971). Generally the velocity difference Detween the two streams is much larger than the Alfien speed and the Instability is stabllized. There is no evidence from spacecraft sbservations (e.g., F1g. 3) or from simulacion (Llewer, 1976; Leroy et al., 1982; Forslund et al., 1984) that 1t does occur. In simulations of oblique shocks, however, Biskamp and Welter (1972) observed a strong Ion-ion interaction, which they attributed to the ion-1on instablitity, excited nonlinearly by potential fluctuations due to whistler waves. Forslund et al. (1972) have attributed the same phenomena to a whistler decay instabllity. This behavior has not been seen in recent sibulations of oblique shocks (2uest et al., 1983; Leroy and Winske, 1983), perhaps because of numerical constraints in the models. (See review by Quest for detalls.)

Although reflected lons do not seem to excite the lon-ion Instability, they can interact with the electrons co produce unstable waves, as shown next.

2. Modifled-two-stream 1nstability

The modifled two stream instability is another well known Instabllity of the early Seventies ( $K r g l l$ and Llewer, 1971). For $B=0$, it is an electrostacic mode that results from the coupling of a lower hybrid wave and a Doppler shifted electron plasma oscillation (Lashmore-Davies and Martin, 1973). For the usual case of electrons d-1fting relative to lo.s along y acroes a homogeneous magnetic fleld $B 2$, the instability propagates almost in the $y$ direction $(\cos \theta=$ $\left.\left(m_{e} / m_{1}\right)^{1 / 2}\right)$. Because the electrons are strongly tled to the magnatic fleld. this constraining motion gives them an effective mass and the Instability is a hydrodynamic mode involving the relative otreaming of the heavy lons and the effectively equally heavy electrons (from which the name "modified two scream" derives). At maximum growth the properties of the wost unstable node are:(McBride et al, 1972)

$$
\begin{aligned}
& \omega_{5}=\frac{i 3}{2}-L H \\
& Y=\frac{1}{2} \omega_{L H}
\end{aligned}
$$


$k=\sqrt{3} \frac{w_{L H}}{v_{d}}$.

For large value of $k_{2} / k$ the Instability goes over to the 1 on acoust 1c mode (which 18 dampej for $\mathrm{T}_{1} \approx \mathrm{T}_{\mathrm{q}}$ ). The modifled tuo stream instability persists for $T_{f}>T_{E}$, but is stabilized by electromagnetic effects when the drift speed exceeds the alfven speed (McBride and $D t t, ~ I 972$ ).

An interesting feature of this instablifty is that it heats both electrons and lons: the lons are heated primarily ir the direction of the current, while the electron heating 18 a:ong the magnetic field. Th1s has been verifled in two-dimensional particle simulations (McBride et al., 1972), that show the nonlinear behevior 18 due to the fact that both electrons and lons become trapped (the unmagnetized lons are trapped by the fluctuating electric field along $k$, while the electrons are trapped by the $E_{\text {q }}$ componert). The amount of heating that could occur at the bow sheck from this instabilit: has been estimated ty Revathy and Lakina (197

As with the lon-iol nstability the aforementioned electromagnetic stabilization that occurs for $v_{d}>v_{A}$ would seem to preclude the possibility of 1t being an effective heating mechanism at the bou shock. The effect of finlte beca on the instabliticy, however, is quite interesting and has been irivestigated extensively cver the last few years (Lemons and Gary, 1977; Wu et al., 1983; Wu et al., 1984; Isa1 et al., 1984). particularly with application to supercritical shocks. $\overline{\text { In }}$ chis case the reflected ions just in front of the shock (in the foot ${ }^{*}$ ) are streaming relative to the incoming solar wind lons (toc fast to excite the ion-1on 1nstablitcy). In the shock normal ( $x$; direction these two Ion species are drifting relative to the ecetions across the magnetic fleld, allowing for the possibility of exciti-3 alectron-ion Instabilities with each ion component.

When $B-1$, the dispersion equation is very complicated and there are no simple analytic expressions. Compared to the $B=0$ result, the growth rate 18 reduced (but still a sizeable fraction of iin), $k^{-}-\mathrm{c} / \mathrm{c}$, and the angle of prupagation $\theta$ 1s more oblique. An example of guch inear results (frow Tsal et al, 1984) 18 shown in Fig. 6 . As $v_{f}$ is Increased beyond $v_{A}$, the Instablitiy is not stabilized, rather $g$ decreases while the corresponding maximum growth rate increases up to $v_{d} / v_{A}-10$ then decreases. The 1.istablitity in this regime results from the coupling of the ion beam with whistler modes (Wu et al, 1983), the hydrodynamic character of the modifled two otream instability is lost, and the mode is more appropriately cermed "the kinetic cross-field straaming Inatab111ty".

An Interesting property of this inscablitity was found by Lemons and fary (1977). They howed that the magnetlc part of the inatability $|B|^{2}$ can be large compared to the electric part $|E|^{2}$, even though the instability is priour1ly electrostatic in origin. This follows by ceparating the electric fleld into its longitudinal and transverse components $\left(E-E_{L}+E_{T}\right)$ and recalling that 
$\underline{\nabla} E_{T}=\frac{-1}{C} \frac{\partial B}{\partial t}$

Since $|\omega / c k|^{2}<<1,|B|^{2} /|E|^{2}$ can be large even thougih $\left|E_{T}\right|^{2} /\left|E_{L}\right|^{2}<<1$. At the bow shock the low frequency electromagne:tc 1.0 ise has often been attributed to whistlers (Rodriguez and Gurnett, 1975 and 1976); the above arguments suggest that much of this low frecuency ( $(100 \mathrm{~Hz}$ ) noise can be due to modes like the kinetic cross-fiela streaming instability. Heating at the bow ahock due to this instability at high beta has also been investigated. Winske et al. (195/4) have worked out a quasilinear theory for the heating paraliel and pi-gendicular tc $d$ for arbitrary $B$. As $B$ increases and the most unstable moile propagates wore obliquely, the electron and ion heating become nore 18utropic. To calculate the actual heating rates the saturation level for the Instability is needed. Computer simulations (Winske et al., 1984) demonstrate that the saturation level decreases with 3 ; this occurs because as beta Increases and the most unstable mucies propagate wnre in the dilection of the magnetic fleld, it beromes sasier to trap the electrons. The heating rates decrease with beta ns we.1, as shown in F18. 7. These results have been apflied to heating : the bow shock, assuming unstable waves are generated both from the presence of reflected and solar wind lons in the foot region. For low $B$, waves due to both species effectively heat the sections, Increasing their parallel temperature across the shock by about a sastor 5-10. At B-1, however, only waves due to the solar wind lons heat ing electrons, but much less effectively, $\Delta T_{e} / T_{e}-40 \%$.

In the ramp region the effect of gradients (Vn, $\nabla T$ ) are also Important, and the kinetic cross-field instabllity acquires a somewhat different character and a new name, the lower hybrid drfft instabllity.

3. Lnwer hybrid drift instability

When $k_{z}=0$ the kinet $1 c$ cross-fleld streaming instablitty is stable. The presence of gradients in density and remperature destabilizes the mode and $1 t$ ts then called the lower hybrid isift instablitty. The distinction between the two instabilities is partly historical and derives from the response of the electrons. In the case of the kinetic cross-field streaming instablitty, :he electrons are free to move along the magnetic fleld, while for the lower hybrid drift instablilty they are strongly constrained because $k_{z}=0$. Actually the two instabllities are limiting cases of the same entity. In a self-consistent equilibrium the cross-field current which would glve rise to the kInetic cross-fleld etreamling instablitiy would be due to gradients and in a three-dimensional system waves with $k_{z}=0$ would form a small subset of the entire spectrum. Thus, the two modes ca.l be combined into a 'Beneralized lower hybrid drift instability" (Hala et al., 1979).

The lower hybrid drift instabllity his been nxtensively studied witn applications to theta-plnch experimerits and the eart, 3 magnetota11 (Krall and ILIewer, 1971; Davidson and Gludd, 1975; $r$ 1, 1976: Davideon et a1.. 1977; Huba et a1, 1981) In such oltuatior the plesma pressure 15 balanced by the magnetic pressire, so that the density gradient and the magnetic flelt gradiant are in opposite directions. (This 1s not on at the shock, as w111 te discussed later.) The Inetability is fluid-1ike for $v_{d}=l v_{n e}+v_{n i} \mid>v_{1}$ with linear properties (for $v_{d} / v_{1}>1$ and $T_{e} / T_{1}<<1$ ): 
$w_{r}=\frac{1}{2^{5 / 6}}\left(\frac{v_{d 1}}{v_{1}}\right)^{1 / 3} w_{\mathcal{L H}}$

$Y=\sqrt{ } 3 w_{r}$

$k=\sqrt{2} \frac{\omega_{L H}}{v_{1}}$

and kinetic for $v_{d} / v_{1}<1$ with characteristics (for $v_{d} / v_{1}<<1$ ):

$\omega_{r}=\frac{1}{\sqrt{2}} \frac{v_{d 1}}{v_{1}} \omega_{L H}$

$Y=\frac{(2 \pi)^{1 / 2}}{8}\left(\frac{v_{d 1}}{v_{1}}\right)^{2} \omega_{L H}$

$k=\sqrt{ } 2 \frac{\omega_{L H}}{v_{1}}$

The instability is rather insensitive to $T_{e} / T_{1}$, but enhanced by $T_{e} / T_{1}<1$, and does not become strollized when the drift speed $v_{d}$ is lowered. (For $v_{d}<<v_{1}, 1 t$ evolves into an ion cyclutron mode (Frcldbers and Gerwin, 1977).)

The heating rates and collision frequency for the lower hybrid drift Instabllity have been calculated by Dayidson and Gladd (1975) and Gary (1980), who flnds $\left(T_{e} / T_{1}<<1\right)$ :

$v^{\star}=\frac{(2 \pi)^{1 / 2}}{10}\left(\frac{T_{1}}{T_{e}}\right)^{5 / 4}\left(\frac{V_{d 1}}{V_{1}}\right)^{2} \omega_{L H}$ 
$v_{T 1}=\frac{(2 \pi)^{1 / 2}}{15}\left(\frac{T_{1}}{T_{e}}\right)^{1 / 4}\left(\frac{v_{d 1}}{v_{1}}\right)^{4} \frac{v_{e}}{v_{1}} \omega_{L H}$

$v_{T e}=\frac{1}{(10)^{1 / 2}}\left(\frac{T_{1}}{T_{e}}\right)^{5 / 4} v_{T 1}$.

The Instability heats electrons as well as lor. These results have been verified in a number of computer simulations (e.g., Winske and Llewer, 1978; Tanaka and Sato, 1981; Chen et al., 1983 Brackb111 et al. 1984).

The nonlinear turbulence level of the instability was intially estlmatad from the avaljable free energy (Davidson and Gladd, 1975). More recently, computer simulations (again in theta-plnch or neutral sheet geometry,mostly in two dimensions) have been used to calculate the saturation level and to try to determine whether the electrons or the lons are the ultimate dissipative mechaniso (see Winske, 1981 ). Early simulations considered stronger ( $f l u l d-11 k e)$ cases $\left(v_{d}>v_{1}\right)$ and Ion trapping was clearly demonstrated to be the saturation mechanism (W1nske and Llewer, 1978; Tanaka and Sato, 1981). In weaker cases $\left(v_{d} \approx v_{1}\right)$ the saturation process was unclear. In the last few years, however, other simulations of the kinetic reglme ( $\left.v_{d}<v_{1}\right)$ (Chen et al., 1983; Brackbill et al., 1984) have now, with some confidence but not conclusively, shown that the electrons provide th. ultimate dissipation through $\nabla_{B}$ resonance effects, consistent with recent nonlinear theory (Drake et al., 1983 and 1984).

In the shock geometry the situation 18 somewhat different, because the density gradient and magnetic fleld gradient are in rhe same direction. In this case the usual lower hybrid drift mode is stable (Lemons and Gary, 1978), although it can be destab1lized by an electron temperature gradient (2hou et al., 1983). Th1s is shown in Fig. 8 , frow Zhou et al; for $\overline{\tau^{0}} \overline{1} \bar{l}$ the mode 18 stable at $\theta-90^{\circ}$, while for larger values of ${ }^{\circ} \rho_{1}$ the instabllity peaks at $\theta=90^{\circ}$.

Recent two-dimensional simulations of quasiperpendicular shocks (Forslund et al., 1984) show heating of transmitted Ions, in addition t.o the appearance of reflected lons. Figure 9 presents a snapshot of one of the sioulations, howing phase space and the aagnetic fleld structure along the shock normal and wave activity inside the shock layer. The wavelengths and frequencles of the strong fluctuat lons that are observed in the calculation are typlcally c/we and $\omega_{2 H}$ respectively. An analysis of these waves (F18. 9d) using profites obtained from the simulation (Aldrich et al., 1983) has shown that the frequencles and wavelengths are consistent with the lower hybrid drift Instabllity (with $k \neq 0$ ) of zhou et al. (1983). Waves are also

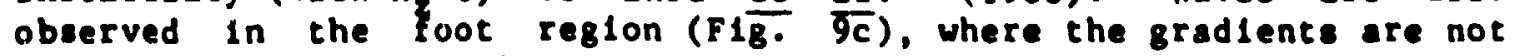
predominant (F18. 9b) but the reflected lons form a distilct population (F18. 9a). The waves here call be attributed to the interaction of both lon components with the elecrons via the kinetic crose-fleld orreating Instablitty (Wu et al., 1984). These lower hybrid-likw waves in the sloulation are consiatent with the low 
frequency electromgnet le waves uoually observed at bow shock crossings (Rodriguez and Gurnett, 1975 and 1976).

Finally, we conclude th's subsection with ar important point, ade by Lewone and Gary (1979). wlthough the lower hybrid drift and kinetic crose-field etreaning instability have auch lower chresholds than the Ion acoustic Instablity, the shock widch lo betcer fit by a condition basec on the arginal stability velocity of the ion acoustic Instabllity (Morse and Greenstadt, 1976; Greenstadt et al., 1978). The reason is that the anowalous resistivity of these lower hybrid nodes 18 wuch saller than that of tie lon acoust1c, because the long wavelength bodes are wuch less effective at slowing down the electrons. siallarly, the heating rates associated with these modes are also saller than those of the Ion acoustic Instability.

D. Other Instablities

We briffly discuss severa + other instabilities which have been considered in relation to heacing et shocks.

1. Electron uhistler instability. This mode is driven by a

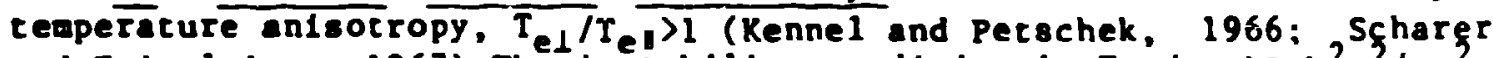
and Trivelpiece, 1967) The instability condition $18 \mathrm{~T} / \mathrm{T}_{\mathrm{el}}>1+\mathrm{k}^{2} \mathrm{c}^{2} / \mathrm{w}_{\mathrm{e}}{ }^{2}$; typirall; , $\omega_{T}-Y^{-} \Omega_{e}$. The linear and nonlinear properties are well known (Ossakow et al, 1972). In the shcck th1s mode can arise because of consezvation of magnetic moment at the quasiperpendicular shock Increases $I_{\text {el }}$ (see Wu er $31 ., 1984$; review by Gurnett).

2. Electromagnet $\overline{\bar{j}} \bar{c}$ Ton cyclotron Instabllity. This instability is similar to the previous, except that the anisotropy is in the Igns. The 1 inear and quasilinear properties $\left(\omega_{r}-\Omega_{1}, h_{\eta}-\omega_{1} / c, Y^{-}-\partial_{1}\left(B_{1} / 2\right)^{1 / 2}\right)$. are found in Davidson and Ogden (1975); the nonlinear behavior has been cimulated by Tajima et al. (1977). The instability provides a nechanism to isotropliz the reflected lons when they gyrace downstream and pernit some of them to escape along fleld lines back into the foreshock (Lee et al, 1981; Tanaka et al, 1983; review by Goodrich).

3. Whistler decay instability. This mode has been asjcussed brief Iy with respect to the Ion-ion instability. It provides a means of producing short wavelength electrostatic surbulence (and a way to heat lons) at quasiparallel shocks (see review by Quest).

4. Beaw driven Ion acoustic Inscabilicy. Within the shock ramp

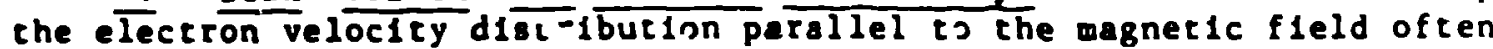
shows a beam-like protrulion on the ingoing edge of the developing flatcop (e.8.. F18. 4). LI ear analysis shows such distributions can be ul.stable to ion acoustic wides, which way play a role in heating and flatcening of the electron dittribution (Thomsen et al., 1983; Feldwan revieu).

5. Lower hybrid and 10 accustic relocity ring distributions. The

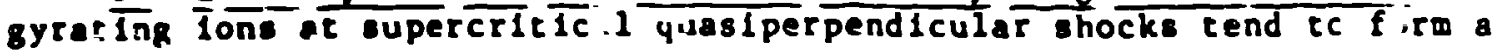
ring-like velocity distribution. Which can be unstable to a variety of modes (Hu et al., 1984). Such instabilities may explain some of the turbulence which is observed downstesw of the nain shock tranbl:ion (Rodrlguez and Gurnete, 1975; Formisano and Torbert, 1982).

\section{T.V. Conclusions}

We conclude by reviewing the progrese made over the last decade and werizing the current etatus of ovi understanding ci diselpation procesese in collisionless shocks. During ihe last ten years the number of Instabilities (theorists say) which can oc'-ur at ahocks has 
not grown appreclably, although how much we know about the various wave modes has increased a good deal. For example, In recent years linear analysis has becone more sophisticated (Improved calculations of $\nabla B$ effects) and has been applied to more realistic shock-1ike geometries (self-consistent equilibria with all gradients, Inclusion of reflected lons for supercritical shocks). There have also been a number of new computer simulations of some of the lnstabilitles (lower hybrid drift, kinetic cross-field streaming instablittles), which have led to a better understanding of their nonlinear behavior and which have been folded into calculations of their transport properties.

Even with the advances of the last decade, a number of key questions concerning microinstabilities remain unanswered. While the role of the Ion acoustic instability for plasma heating at shocks when $T_{e} / T_{1} \gg l$ remains undisputed, the issue of the dissipation mechanism for

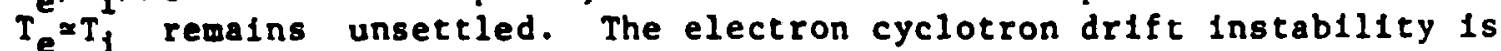
usuafly dismissed because of 1 ts low saturation level; but as has been discussed here, it has a nonlinear behavior which is not easily described and which depends in part on the geometry and the presence of turbulence. How Important such effects are at the shock for the various instabilities (not just the electron cyclotron drift) is unknown. Another unanswered question concerns the origin of the strong heating of lons at laminar shocks with $T_{e} / T_{1} \gg 1$ (F1g. 2). Although in this case the ion acoustic instability is the natural candidate, it generally produces ion talls, rather than bulk heating. In this case, however, the principal evidence cowes from simulations in idealized geometries with unmagnet:zed lons; again, the effect of the instability in the shock layer may be somewhat different. In these shocks beta is low enough that the lon heating rate due to the rodified two stream Instability is large enough to explain the oboerved heating (Thomsen et al., 1984). Simulations of such shocks (Forslund et al., 1983), however, do not show any evidence for wave growth or turbulent heating, even though it is predicted by linear theory and seen in the simulations at higher Mach numbers (Aldrich et al., 1983; Forslund et a 1., 1984).

The loportance of the iower-hybrid-like modes at high beta is also not settled. While these instabilities can lead to signjficant heating at low beta (especially of lons) in laboratory experiments and simulations, their role at the bow shock is still unclear. Finite beta effects (which do not affect the shorter wavelength, electrostatic modes) stabilize the lon-ion instabllity, reduce the growth rates of the lower hybrid drift instablity, and significantly lower the saturation level of the kinetic cruss.rifeld streaming instablitty. In addition, the heating rates of these modes seem too omull to heat the lons very much at the bow shock, although they could generate (some) of the oboerved low frequency, electromagnet ic nolse.

There are number of ways in which theory can be laproved in order to resolve some of these questions over the next few ycars. For example, elmost all of the IInear analysis which t.as been done Involves local theory. Although such calculations are valuable for determining under what conditions instablilties should be operative, it should be noted that nonlocal effects (e.8., Huba et al., 1980) can significantly modify the nature of come Instabilities. What is needed most are some detsiled linear calculations using measured plasma parameters and distribution functions, which are then compared to the actual wave observations. 
Such Improved IInear analysis $w$.d \&lso impact on better estimates of plasma heating at shocks due to the vartous instabilites. Further advances in transport calculations can be expected in the future. For example, nonlocal quasilinear theory 18 still in the embryonic stage (e.g., Sgr, and Gladd, 1983) and w111 someday find application to shocks.

The best method for understanding microscopic processes at shocks remains computer simulation. The development of new implicit methods of particle simulation (Brackb111 and Forslund, 1982) soupled with advances in the $81 z$ and speed of computers allows the possibility of tackling problems on a scale that was impossible a decade ago. Generally the study of Instabilities by simulation has invol red .... elmplest of geometries. Such calculations need to be extended now to shock-like geometries to Investigate the role of the nonlocal and nonlinear effects mentioned previously. Simulations of heating in laminar shocks at LOB Alamos indicate some progress is being made in this area at the present time.

To sum up, the study of dissipation processes remains one of the most important research areas in collisionless shocks. In splte of a basic corsensus on the Importance of instablifties and wave-particle interactions, a mature theory base, "and recent advances in observations, theory and simulation, a number of fundamental questions remain unanswered.

Acknowledgements

I wish to thank Drs. Peter Gary, Michelle Thomsen, and Ching Wu for their comments and suggestions. This work was supported by the NASA Solar Terrestrial Theory Program and the Dept. of Energy. 
References

Aldr1ch, C. H., J. U. Brackb111, D. W. Forslund, K. Lee, K. B. Quest, and D. Winske, Wave turbulence in quasiperpendicular shocks, EOS Trans., 64, 824, 1983.

Auer, P. L., R. W. Kilb, and W. F. Crevier, Thermalization in the earth's bow shock, J. Geophys. Res., 76, 2927, 1971.

Biskamp, D. and R. Chodura, Computer simulation of anomalous dc resistivity, Phys. Rev. Lett, 27, 1553, 1971.

Biskamp, D. and R. Chodura, On the nonlinear electron cyclotron drift Inctability, Nui'. Fusion, 12, 485, 1972.

Biskamp, D. and H. Welter, Structure of the earth's bow shock, J. Geophys. Res., 77, 6052, 1972.

Biskamp, D., Colisistonless shock waves in plasmas, Nucl. Fusion, 13 , $719,1973$.

B1skamp, D. and R. Chodura, Collisionless dissipation of a cross fleld electric current, Phys. Flulds, 16, 893, 1973.

Brackb111, J.U. and D.W. Forslund, An Implictt method for electromagnetic plasma simulation in two dimensions, J. Comp. Phys., $46,271,1982$.

Brackbill, J. U., D. W. Forslund, K. B. Quest, and D. Winske, Nonlinear evolution of the lower hybrid drift instability, Phys. Fludds, to te submitted, 1984.

Chen, Y.-J., W. M. Nevins, and C. K. B1rdsall, Stabillzation of the lower hybrid drift Instability by resonant electrons, Phys. Flulds, 26, $2501,1983$.

Davidson, R. C., N. A. Krall, K. Papadopoulos, and R. Shanny, Electron heating by electron-1on beam instablitiles, Phys. Rev. Lett., 24, 579,1970 .

Davidson, R. C. and V. T. Gladd, Anomalous transport properties assoclated with the lower hybrid drift instability, Phys. Fluids, $18,1327,1975$.

Davidson, R. C. and J. M. Ogden, Electromagnetic ion cyclotron instability driven by ion energy anisotropy in high beta plasmas, Phys. Flulds, 18, 1045, 1975.

Davidson, R. C., N. T. Gladd, C. S. Wu, and J. D. Huba, Effects of finite plasma beta on the lower hybrid drift instablity, Phys. Fluids, 20, 301, 1977.

Davidson, R. C. and N. A. Krall, Anomalous transport in hlgh temperature plasmas with applications to solenoldal fusion systems, Nucl. Fuston, 17, 1313, 1977.

Drake, J.F., P. N. Guzdar, and J. D. Huba, Saturation of the lower hybrid drift instability by mode coupling, Phys. Flu1ds, 26, 601, 1983.

Drake, J.F., P. N. Guzdar, A. B. Hassam, and J. D. Huba, Nonlinear mode coupling theciry of the lower hybrid drift instablilty, Phys. Flu1ds, 27, in press, 1984.

Dum, C. T., R. Chodura, and D. Blskamp, Turbulent hasting and quenching of the Ion sound Instab111ty. Phys. Rev. Lett., 32, 1231, 1974.

Dum, C. T., Anomalous heatin; by Ion sound turbulence, Phys. Fluids, $21,945,1978 a$.

Dum, C. T., Anowalous electron transport equations for 1on ound and related turbulent spectra, Phys. Flu1ds, 21, 956, $1978 \mathrm{~b}$.

Dum, C. T, and R. Choduca, Anomaloue transition from Buneman to 1 on sound Instabllity, In Wave Instabl11t1es In Space Plasmas, edited by P. J. Palmades8o and K. Papadopoulos, P. $\overline{13} 5$, D. Reldel, 1979. 
Feldman, W. C., R. C. Anderson, S. J. Bame, S. P. Gary, J. T. Gosling, D. J. MeComas, M. F. Thomsen, G. Paschmann, and M. M. Hoppe, Electron velocity distributions near the earth's bow shock, J. Geophys. Res., 88, 96, 1983.

Feldman, W.C., Electron yelocity distributions near collisionless shocks, Charman conference on coll1sionless shocks, AGU, 1984.

Formisano, $V$. and $R$. Torbert, Ion acoustic vaveforms generatsd by Ion-ion streams at the earth's bow shock, Geophys. Res. Lett., 9, 207,1982 .

Forslund, D. W., R. L. Morse, and C.W. N1elson, Electron cyclotren drift Instability, Phys. Rev. Lett., 25, 1266, $: 970$.

Forslund, D. W., R. L. Morse, and C. W. Nielson, Nonlinear electron cyclotron drift instability and turbulence, Phys. Rev. Lett., 27, $1424,1971$.

Forslund, D. W., J. M. Kindel, and E. L. Iindman, Parametric excication of electromagneric waves, Phys. Rev. Lett. $=29,249,1972$.

Forslund, D. W., K. B. Guest, C. H. Aldrich, J. U. Brackb111, and K. Lee, Simulatior of subcricical collisionless shocks, EOS Trans., $64,824,1983$.

Forslund, D. W., K. Quest, J. U. Brackbill, and K. Lee, Collisionless dissipation in quasiperpendicular shocks, J. Geophys. Res., 89, in press, 198..

Freidberg, J. P. and R. A. Gerwin, Lower hybrid drift Instability at low drift velocities, Phys. Flulds, 20, 1311, 1977.

Galeev, A. A., Collisionless shocks, In Physics of Solar Planetary Environments, edited by D. J. Will1ams, P. 46\%, AGU, 1976.

Gary, S. P., Wave-particle transport from ejectrostatic instablities, Phys. Fluids, 23, 1193, $198 \mathrm{C}$.

Gladd, N. I., The lower hybrid drift 1nstability and the moditled two stream instability in high density theta pinch environments, Plasma Phys., 18, 27, 1976.

Co: d, S. H., A. W. DeSilva, and J. D. Huba, Jbservation of shock generaced curbulence in a magnetized plasma by $\mathrm{CO}_{2}$ laser scactering, Phys. Flu1ds, 23, 1132, 1980.

Goodrich, C. C., A review of numerical aimulations of quasiperpendicuiar collisionless shocks, Chapman conference on coll1sionless snocks, AGL, 1984 .

Greesstadt, E. W., and R. W. Fredricks, Plegma Instability modes related to the earth's bow shock, In Magnetospheric Physics, edited by B. M. McCormac, p. 281, D. Reldel, 1974.

Greenstadt, E. W., V. Form18a..o, ᄂ. I. Russell, M. Neugebauer, and F. L. Scarf, Ion acougtic etabillty alysis of the earth's bow shock, Geophys. Res. Lett., 5, 399, 1978.

Greenstadt, E. W., and R. W. Fredricks, Shock systems in collistonless plasmas, In Solar Syetem Plasma Physirs, Ed1ted by I. J. Lanzerott 1 , C. F. Kennel, and E. N. Parker, Vol. III, p. 5, North Holland, 1979.

Greenetadt, E. W., C. T. Russell, J. T. Gosilng, S. J. Bame, G. Paschoainn, G. K. Parks, K. A. Anderson, Z̈. L. Scarf, R. R. Anderson, D. A. Gurnett, R. P. LIn, C. S. Lin, and H. Reme, A macroscopic profile of the cypical quasiperpendicular bow ahock: ISEE 1 and 2, J. Geophys. Res., 85, $21: 4,1980$.

Greenetadt, E. W., A review of the structure of the quasiparallel shock, Chapuan conference on coll1sionless shocks, AGU, 1984 . 
Gurnett, D. A., Waves and Instabljities at collisionlefs shocks, Chapman conference on coll1sionless shocks, AGU, 1984.

Hamasak1, S., N. A. Kral1, C. E. Wagner, and R. N. Byrne, Effect of turbulence on theta pinch modeling by hybrid numerical methods, Phys. Flu1ds, 20, 65, 1977.

Hasegawa, A., Plasma Instabllities and Nonlinear Effects, Springer-Verlag, 1975 .

Horton, W., D. Chol, and R. A. Koch, Ion acoustic heating from renormalized turbulence theory, Phys. Rev., A14, 424, 1976.

Horton, W., D. Chol, and R. A. Koch, Scaling law and asymptotic states for Ion acoustic turbulence, Phys. Flu1ds, 22, 797, 1979.

Hsia, J. B., S.M. ChIu, M. F. Hsia, R. L. Chou, and C. S. Wu, Generalized lower hybrid drift Instability, Phys. Fluids, 22, 1737, 1979.

Puba, J. D., J.F. Drake, and N. T. Gladd, Lower hybrid urift Instability in fleld reversed plasmas, Phys. Flulds, 23, 552, 1980.

Huba, J. D., N. T. Gladd, and J. F. Drake, On the role of the lower hybrid drift Instability in substorm dynamics, J. Geophys. Res., 86, $5881,1981$.

Kadomsev, B. B., Plasma Turbulence, Academic, 1965.

Kennel, C. F. and H. E. Petschek, Liolt on stably trapped particle fluxes, J. Geophys. Res., 71, 1, 1966.

Kennel, C. F., An overview of coll1sionless shocks, Chapman conference on collisionless shocks, AGU, 1984.

Klimas, A., A review of the electron foreshock, Chapman conference on collisionless shocks, AGU, 1984.

Krall, N. A. and P. C. Liewer, Low frequency instabilitles in magnetic pulses, Phys. Rev., A4, 2094, 1971.

Krall, N. $\bar{A}$. and A. W. Trivelpiece, Princlples of Plasma Physlcs, McGral1 H111, 1973.

Lampe, M., W. M. Manhe1mer, J. B. McBride, J. H. Orens, R. Shanny, and $R$. N. Sudan, Nonlinear development uf the beam cyclotron 1nstab1lity, Phys. Rev. Lett., 26, $1221,1971$.

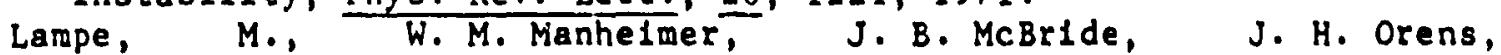
$K$. Papadopoulos, R. Shanny, and R. N. Sudan, Theory and olmulation of the beam cyclotron Instability, Pliys. Fiu1ds, 15, 662, 19728.

Lampe, M., W. M. Manhelmer, J. B. McBride, and J. H. Orens, Anomalous resistance due to cross-field electron-ion streaming instabilities, Phys. Flutds, 15, 2356, $1972 \mathrm{~b}$.

Lampe, M., I. Haber, J. H. Orens, and J. P. Boris, Two-dimensional study of electron-1on streaming instablittles, Phys. Fluids, 17, $428,1974$.

Lampe, M.,W. M. Manhelmer, and K. Papadopoulos, Anomalous transport coefficients for HANE applications due to plasma microinatablilties, NRL Memorandum Report 3076, 1975.

Lashmore-Davies, C. N., and T. J. Mart1n, Electrostatic 1nstahilities driven by an electric current perpendicular to a magetic field, Nucl. Fusion, 13, 193, 1973.

Lee, K., J. U. Brackb111, D. W. Forslund, and K. Quest, Diselpation of reflected lon beams from quasiferpendicular hocks due to electromagnetic ion cyclotron inatability, EOS Trans:, 62, 1011, 1981.

Lemons, D. S. and S. P. Gary, Electromagnetic effects on the modifled two stream Instabll1ty, J. Geophys. Res., 82, 2337, 1977. 
Lemons, D. S. and S. P. Gary, Current-driven Instab111t1es in a laminar perpendicular shock, J. Geophys. Res., 83, 1625, 1978.

Leroy, M. M., D. Winske, C. C. Goodrich, C. S. Wu, and K. Papadopoulos, The structure of perpendicular bow shocks, J.Geophys. Res., 87, 5081,1982 .

Leroy, M. M. and D. WInske, Backstreaming lons from oblique earth bow shocks, Annales Geophys., 1, 527, 1983.

Llewer, P. C. and N. A. Kralis, Self-consistent approach to anomalous resistivity applied to theta-pinch experiments, Phys. Flulds, 16, 1953, 1973.

Llewer, P. C., Numerical studies of ton reflection in collisionless theta-pinch implosions using a hybrid viasov fluid model, Nucl. Fuston, 16, 817, 1976.

Manhelmer, W. M. and J.P. Boris, self-consistent theory of a cullisionless, resistive shock, Phys. Rev. Lett., 28, 659, 1972.

MCBrIde, J. B. and E. Ott, Electromagnetlc and finite $B$ effects on the modifled two stream Instab111ty, Phys. Lett, 39A, 363, 1972.

McBride, J.B., E. Ott, J. P. Bor1s, and J. H. Orens, Theory and simulation of turbulent neating by the modified two stream Instability, Phys. Flulds, 15, 2367, 1972.

Morse, D. L. and E. W. Greenstadt, Thickness of magnetic structures associated w1th the earth ${ }^{-8}$ bow shock, J. Geophys. Res., 81, 1791, 1976.

Morse, R. L. and C.W. Nlelson, studies of turbulent heating of hydrogen plasmas by numerical simulation, Phys. Rev. Lett., 26, 3 , 1971.

Ossakow, S. L., F. Ott, and I. Haber, Nonlinear evolution of whistler Instablittes, Phys. Fluids, 15, $2314,1972$.

Papadopoulos, K., Ion thermalization in the earth's bow shock, J. Geophys. ReB., 76, 3806, 1971.

Papadopoulos, K., R. C. nav1dson, J. M. Dawson, I. Haber, D. A. Hammer, N. A. Krall, and R. Shanny, Heating of counterstreaming ion beams in an external magnetic field, Phys. Fluids, 14, 849, 1971.

Papadopoulos, K., A review of anomalous resistivity for the lonnsphere, Rev. Geophys. Space Phys., 15, 113, 1977.

Papadopoulos, K., Microphysics of collisionless shocks, Chapman conference on coll1sionless shocks, AGU, 1984.

Prlest, E. R. and J. J. Sanderson, Ion acoustic instability in coll1sionless shocks, Plasma Phys., 14, 951, 1972.

Quest, K. B., D. W.Forsiund, J. U. Bracirbill, and K. Lee, Collisionless diseipation processes in quasiparallel shocks, Geophys. Res. Lett., $10,471,1983$.

Quest, K. B., A review of the imulations of quasiparallel coll1sionless hocks, Chapman conference on collisioniess shocks, ACU, $1 \forall 84$.

Revathy, P. and G. S. Lakina, Ion and electron heating in the earth" bow hock region, J. Plasma Phys., 17, 133, 1977.

Robson, A. E., A review of the evolution of lon distributions acrose collibionles shocks in the laboratory and space, Chapman conference on collisionless shocks, AGU, 1984.

Rodflguer, P. and D. A. Gurnett, Electrostatlc and electromagnet1c curbulence aseoclated with the es $h^{-}$bow shock, J. jeop is. Res.., $80,19,1975$. 
Redriguez, P. and D. A. Gurnett, Correlation of bow shock plasma wave turbulence with solar wind parameters, J. Geophys. Res., 81, 2871, 1976.

Russe11, C. T., M. M. Hoppe, W. A. LIvesey, J. T. Gosling, and S. J. Bame, ISEE- 1 and 2 observations of laminar bow shocks: velocity and tnickness, Geophys. Res. Lett., 9, 1171, 1982.

Sagdeev, R. Z. and A. A. Galeev, Nonlinear Plasma Theory, Renjamin, i969.

Scharer, J.E. and A. W. Trivelpiece, Cyclotron wave instabilities in a plasma, Phys. Fluids, 10, 591, 1967.

Sckopke, N., G. Paschmann, S. J. Bame, J. T. Gosling, and C. T. Russell, Evclution of 10r. distributions across the nearly perpendicular bow shock: specularly and nonspecularly reflected Ions, J. Geophys. Res., 88, 6121, 1983.

Sgro, A. G., Calculations of the effects of Incomplete preionization in high voltage theta pinches, Phys. Fluids, 21, 1410, 1978.

Sgro, A. G. and N. T. Gladd, The lower hybrid drift instabilicy near the separatrix of a fleld reversed configuracion, Bull. A.P.S., 28 , 124 i, 1983.

Sleeper, A. M., J. Weinctock, and B. Bezzerides, Nonlinear theory and angular spectrum of the ion acoustic instability, Phys. Fluids, I6, $1508,1973$.

Soldner, F., C. I. Dum, and K. -ll. Steuer, Electron and Ion heating in a high volcage belt plnch, Phys. Rev. Lett., 39, 194, 1977.

Tajima, I., K. MIma, and J. M. Dawson, Alfven ion cyclotron Instablitey: 1ts physical mechanism and observacion in computer simulaticn, Phys. Rev. Lete., -9, $201,1977$.

Tanaka, $M$. and $T$. Sato, Simulations of lower hybrid drift instability and anomalous resistivity in the magnetic neutral sheet, J. Geophys. Res., 86, 5541, 1951 .

Tanaka, M., C. C. Goodrich, D. Kinske, and K. Papadopoulos, A source of the backstreaming ion beams in the foreshock region, J. Geophys. Res., 88, 3046, 1983.

Thomsen, M. L., H. C. Barr, S. P. Gary, W. C. Feldman, and T. E. Cole, Stability of electron distributions within the earth's bow shock, J. Geophys. Res., 88, 3035, 1983.

Thomsen, M. L., A review of uperthermal lons and related waves in the Ion foreshock, Chapman conference on collisionless shocks, AGU, 1984.

Thomsen, M. L., J. T. Gosling, S. J. Bawe, and M. M. Mellote, Ion and electron heating at the subcritical bow shock, i. Geophys. Pes., to be submitted, 1984 .

Tidman, D. A. and N. A. Kral1. She.k Waven in Collision.ess Plasmas. W11ey, 1971 .

Toa1, S. T., M. Tanaka, J. D. Gaffey, E. H. da Jornada, and C. S. Wu, Effect of electron thermal anisotropy on the kinetic crosefield etreaming instability. Phys. Fluide, 27, in prese, 1984.

Toytovich, V. N., An Introduction to the Theory of Plasma Turbulence, Pergamon, 1972.

Wagner, C. E., K. Papadopoulos, and J. llaber, Electromagnctic and Inite Be effects on the counteratreating ion instablitty. Pr. A. Lete., 35A, 640,1971 .

Wesson, J.A. and A. Sykes, Theory of lon sound resietivity, Phye. Rev. Lett., 31, 449, 1973. 
Winske, D. and P. C. Llewer, Partlile simulation studies of the lower hybrld drift 1nstab1l1ty. Phys. Flu1ds, 21, 1017, 1978.

Winske, D., Simulation of the lower hybrid drift instabilicy, $U$. of Maryland Plasma Preprint PL 82-001, 1981.

Winske, D., M. Tanaka, and C. S. Wu, Plasma heating due to the kInetic cross-field etreeming Instability, Phys. Fluids, to be suboltted, 1984.

Wu, C. S. and R. W. Fredricks, Cyclotron drift Instability in the bow shock, J. Geophys. Res., 77, 5585, 1972.

Wu, C. S., Physical mechanisms for turbulent dissipation in coll18ionleos shock waves, Space Sc1. Rev., 32, 83, 1982.

Wu., C. S., Y. M. Zhou, S. T. TsaI, S. C. CuO, D. Winske, and K. Papadopoulos, A kinetic cross-field streaming Instability, Phys. Flu1ds, 26, 1259, 1983.

Wu, C. S., D. Winske, Y. M. Zhou, S. T. Tra1, P. Rodriguez, M. Tanaka, K. Papadopoulos, A. Akimoto, C. S. LIn, M. M. Leroy, and C. C. Goodrich, Microlnstabllities associated with a high Mach number perpendicular bow shock, Space Sc1. Pev., 36, in press, 1984.

Zhou, Y. M., H. K. Wong, C. S. Wu, and D. WInske, Lower hybrid drift Instablitty with temptrature gradient in a perpendicuar shock wave, J. Geophys. Res., 88, 3026, 1983.

zhou, Y.M., Y.Y.L1, and C. S. Wu, Stabilization of electron cyclotron drift instability by magnetic fleld gridiert in a perpendlcular shock wave, Phys. Flulds, 27, submitted, .984 . 


\section{Figure captions}

Figure 1 Geometry of a perpendlcular shock showing the fleld structure and sources of free energy (Wu, 1982).

Figure 2 Bow shock crossing of August 27, 1978 showing electron (sol1d curve) and lon (dashes and circles) densities, flow speed, and 1 on and electron temperatures (max and min) (Thomsen, et al., 1984).

Figure 3 Bow shock crossing of November 7, 1977 showing electron and reflected ion densities, proton and electron temperatures, flow speed, electron pressure, magnetic ficld magnitude and orlentation (Sckopke, et al., 1983).

Figure 4 Evolution of the electron velocity distribution across the bow shock for the December 13.1977 crossing from upstream (BS) to downstream (MS) (Feldman et al., 1983).

Figure 5 Electric fleld spectrum at 6 sec intervals through the shock crossing of Nov. 7, 1977 (from Wu. et al., 1984).

Figure 6 Kinetic cross fleld streaming instablity: real (sclid curves) and lmaginary (dashed curves) parts of the frequency of the most unstable mode (maximlzed over $k$ ) versus propagation angle $\theta$ for various valies of $v_{d} / v_{A}$ (Tsal et $a l$. 1984).

F1gure 7 Heating rates $\left(\Lambda_{\alpha}-\left(\omega_{L H} T_{\alpha}\right)^{-1} d T_{\alpha} / d t\right)$ versus $B_{1}$ for the kinet1c cross-field streaming Instability (Winske et al., 1984).

Flgure 8 Lover hybrid drift Instabllity: growth rate maximized over vavenumber versus propagation angle $\theta$ for varlous values of the electron temperature gradient (2hou et al., 1983).

Figure 9 Simulation results fur high Mach number quasiperpendicular shock (from Aldrich et al., 1983; Forslund et al., 1984): (a) phase space showing reflected lons, (b) magnetic fleld profile, (c) contour plot of lectric fleld $\left(E_{y}\right)$ at $X=12.5$, (d) $E_{y}$ at $X \simeq 12.5$. 


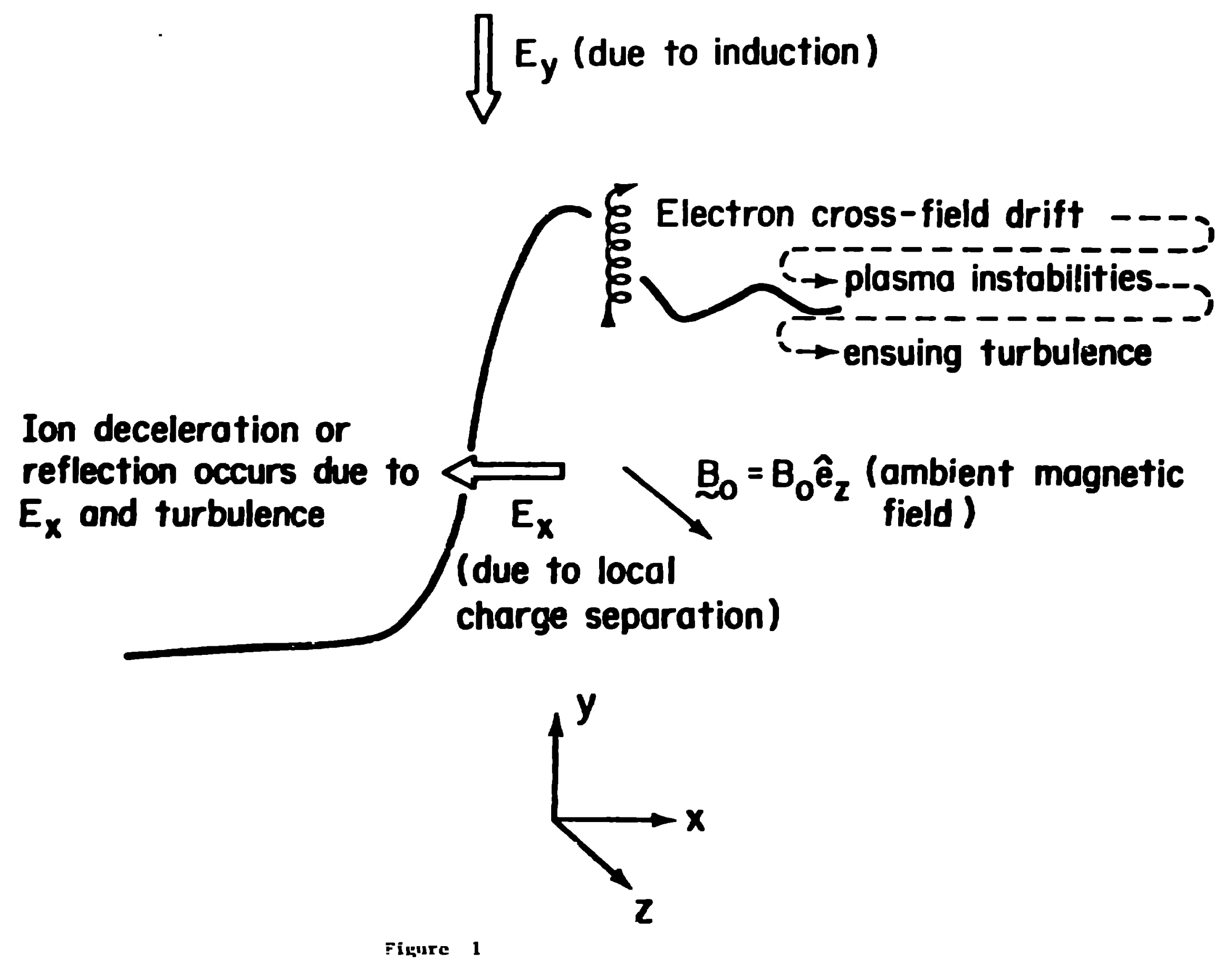




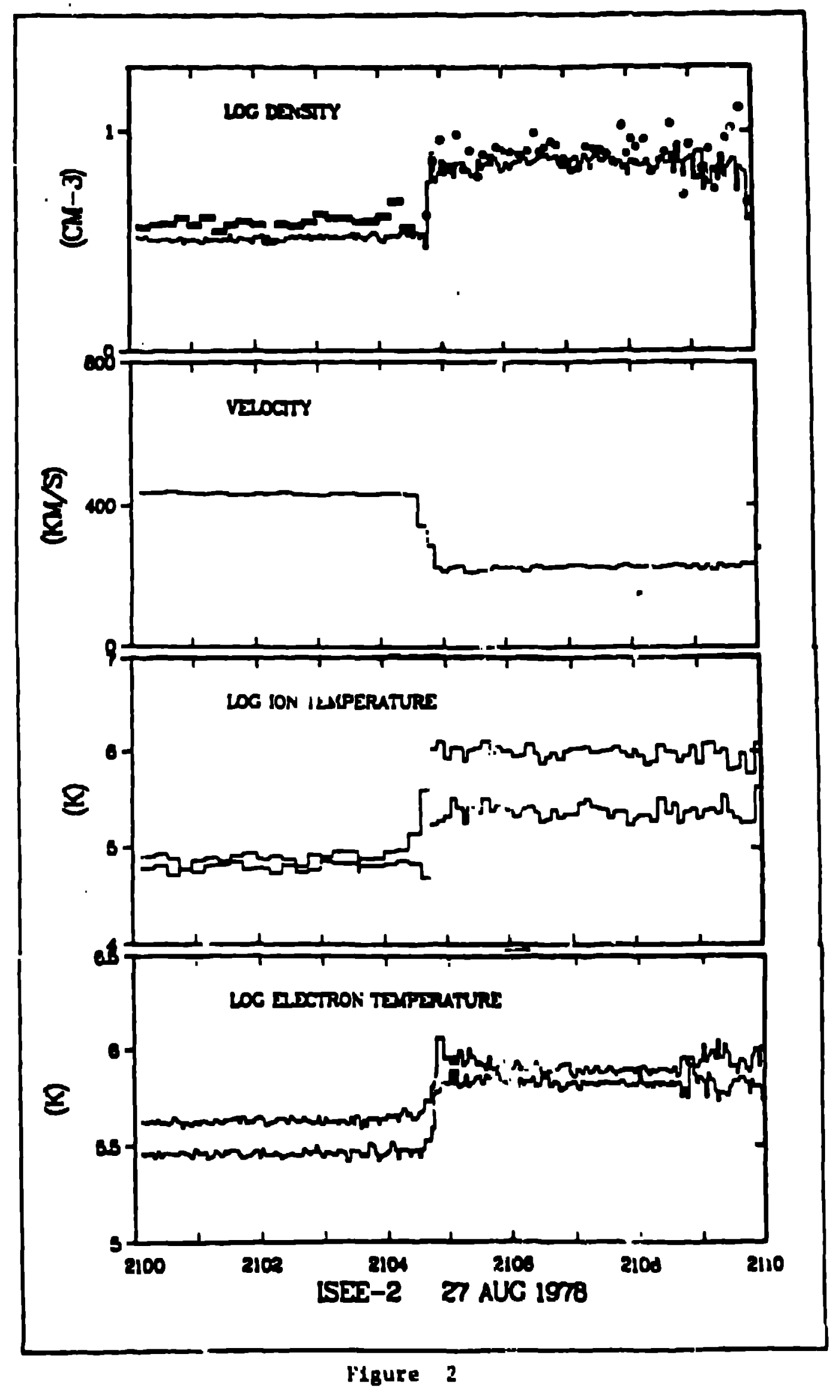




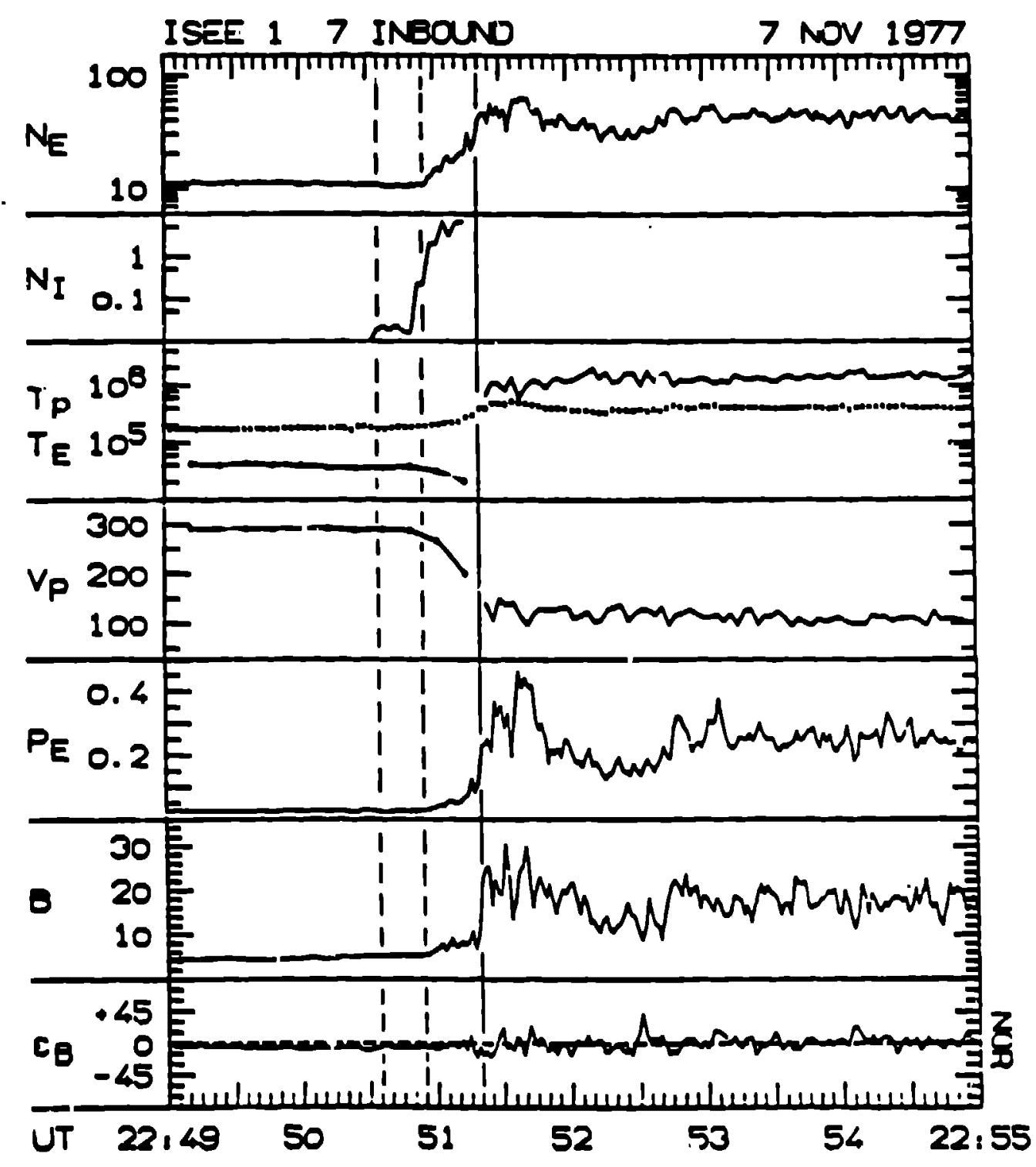

Flgure 3 


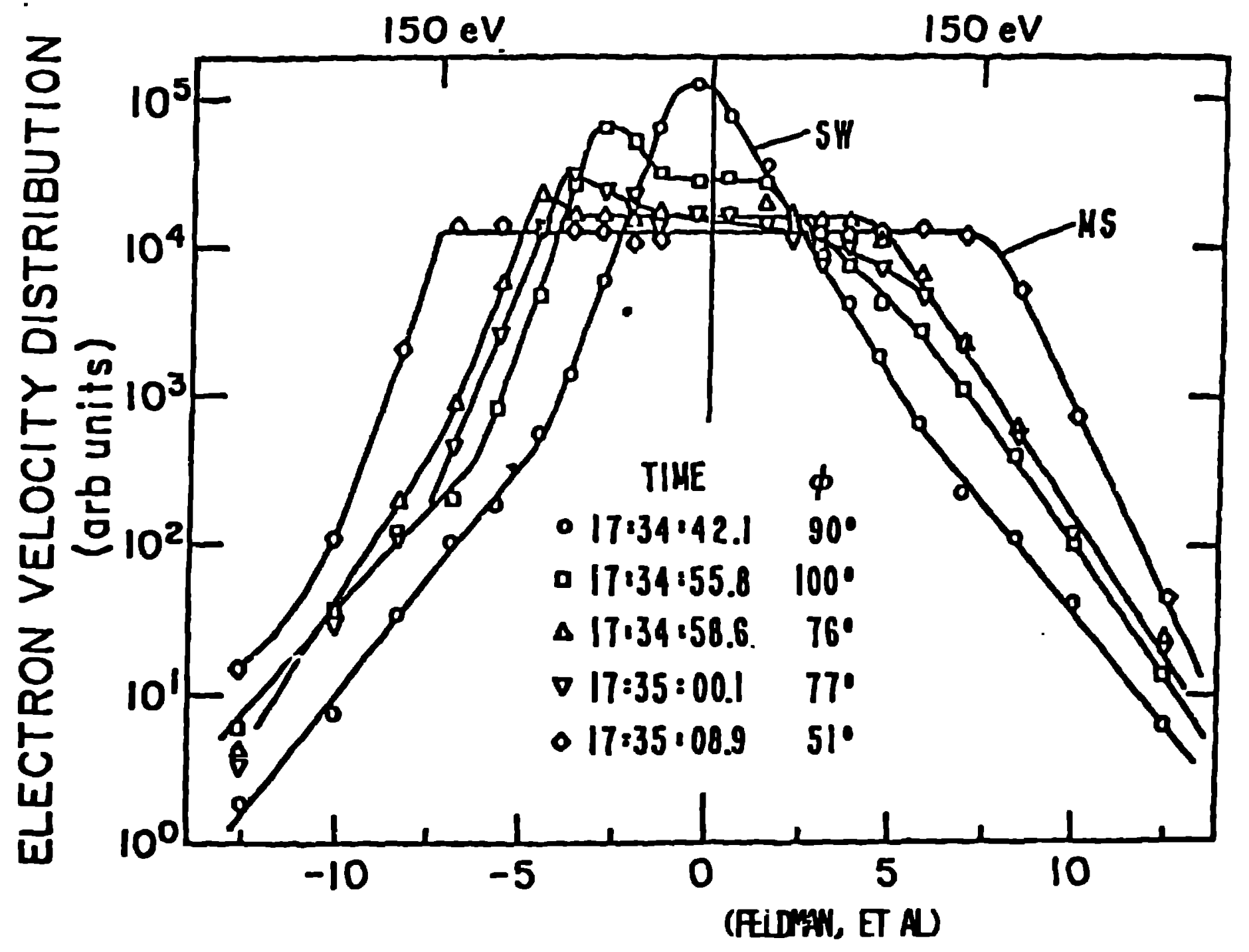

Figur. 4 


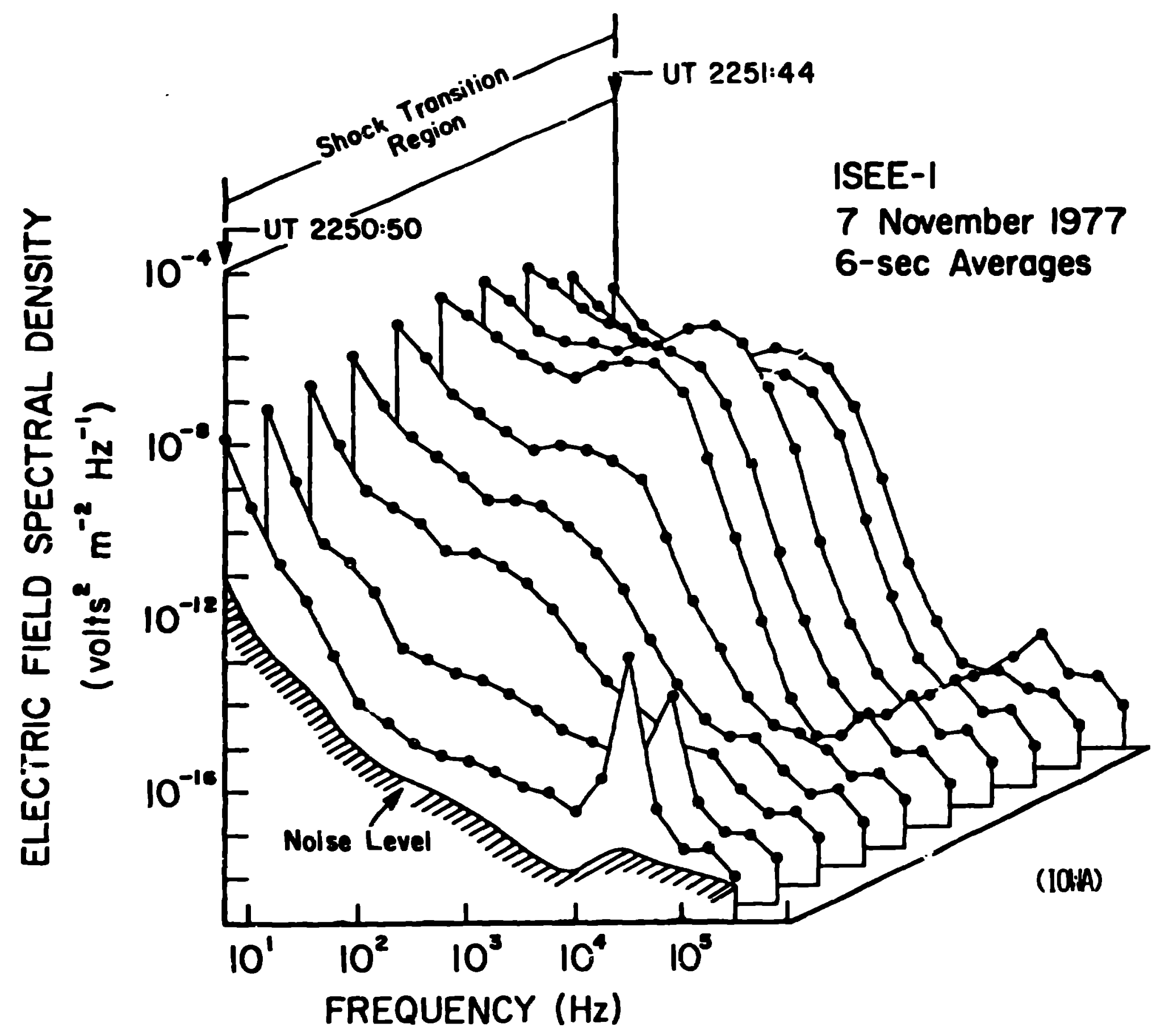

Figure 5 


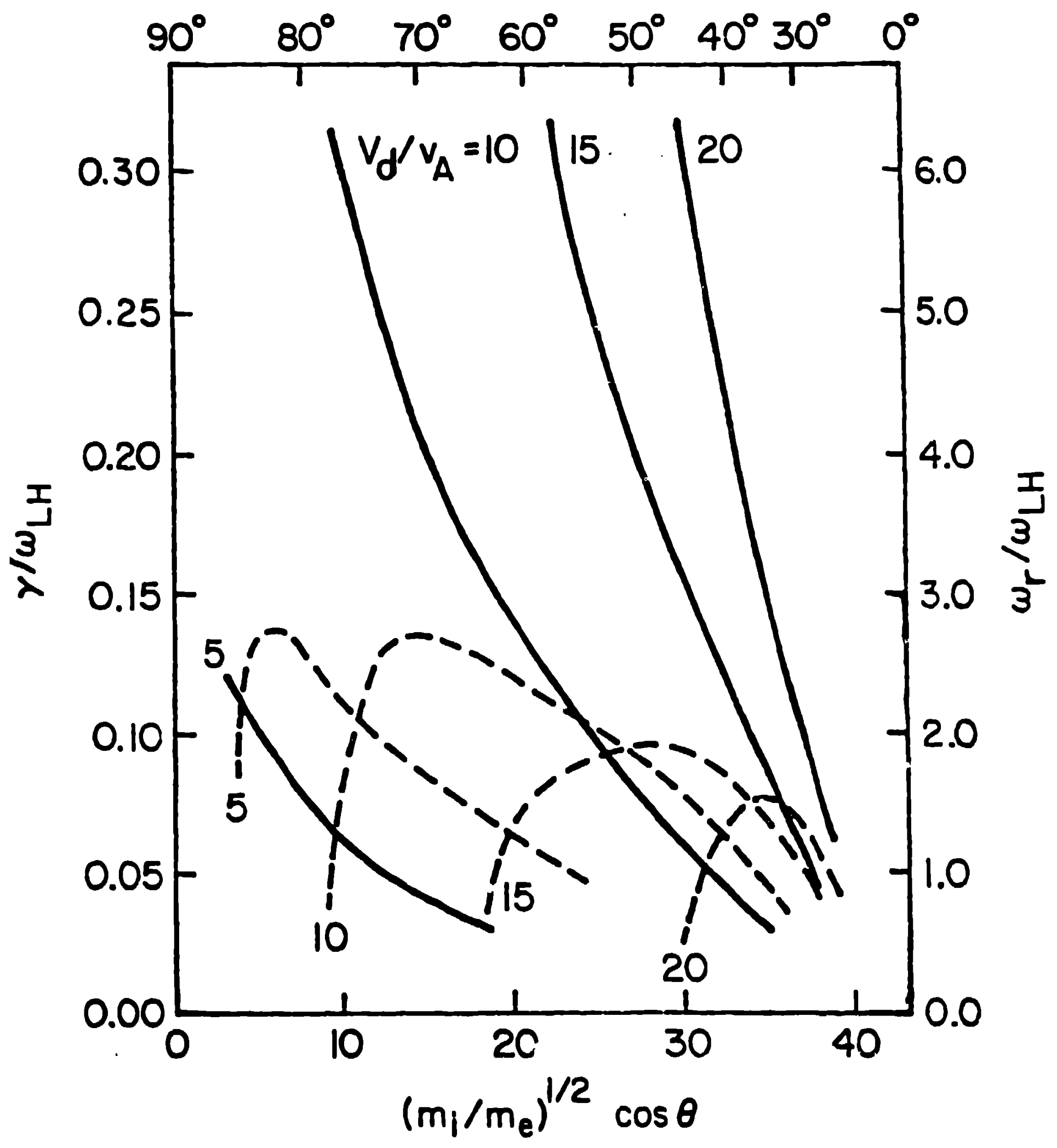

Figure 6 


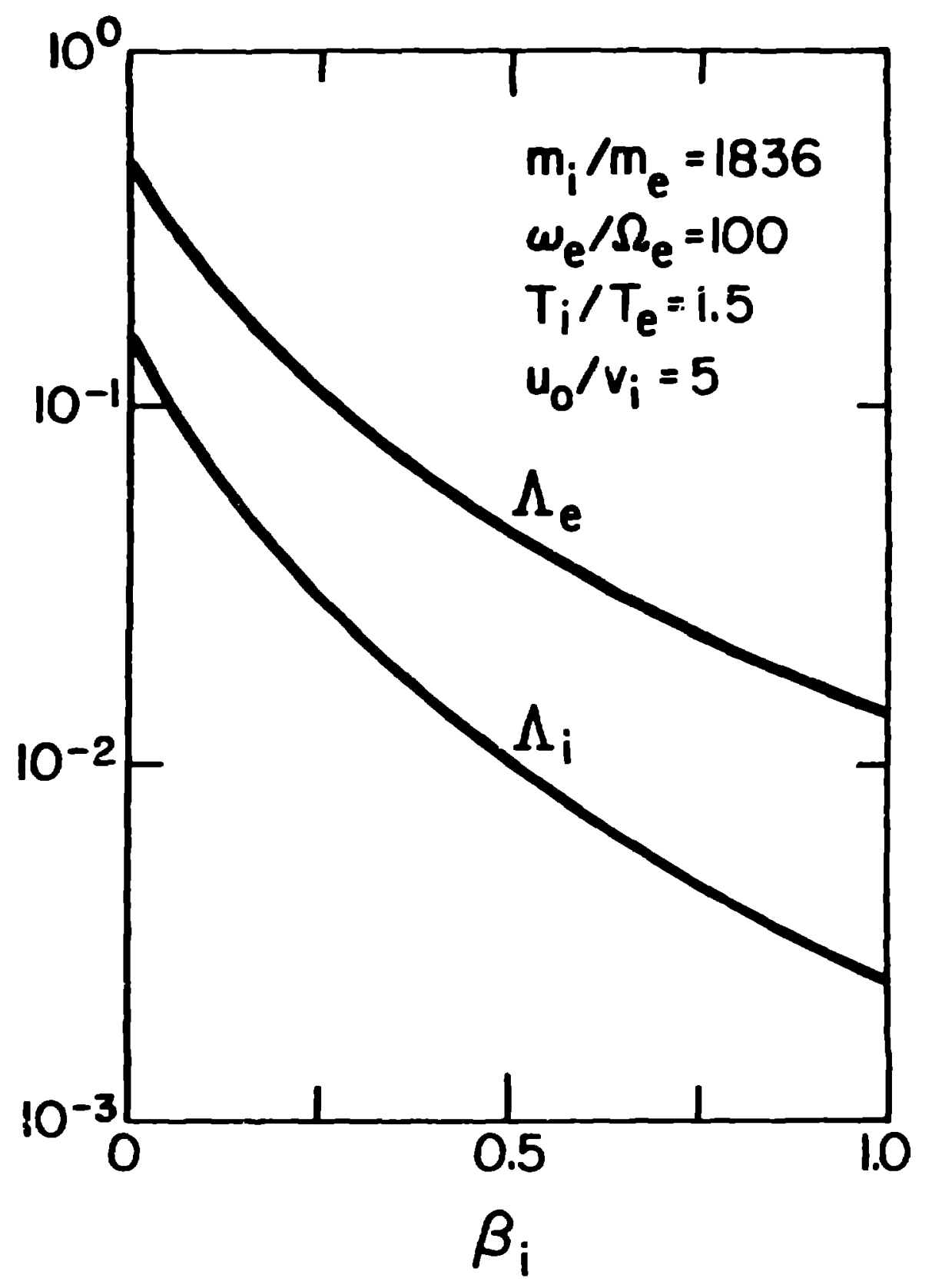

Figure 7 


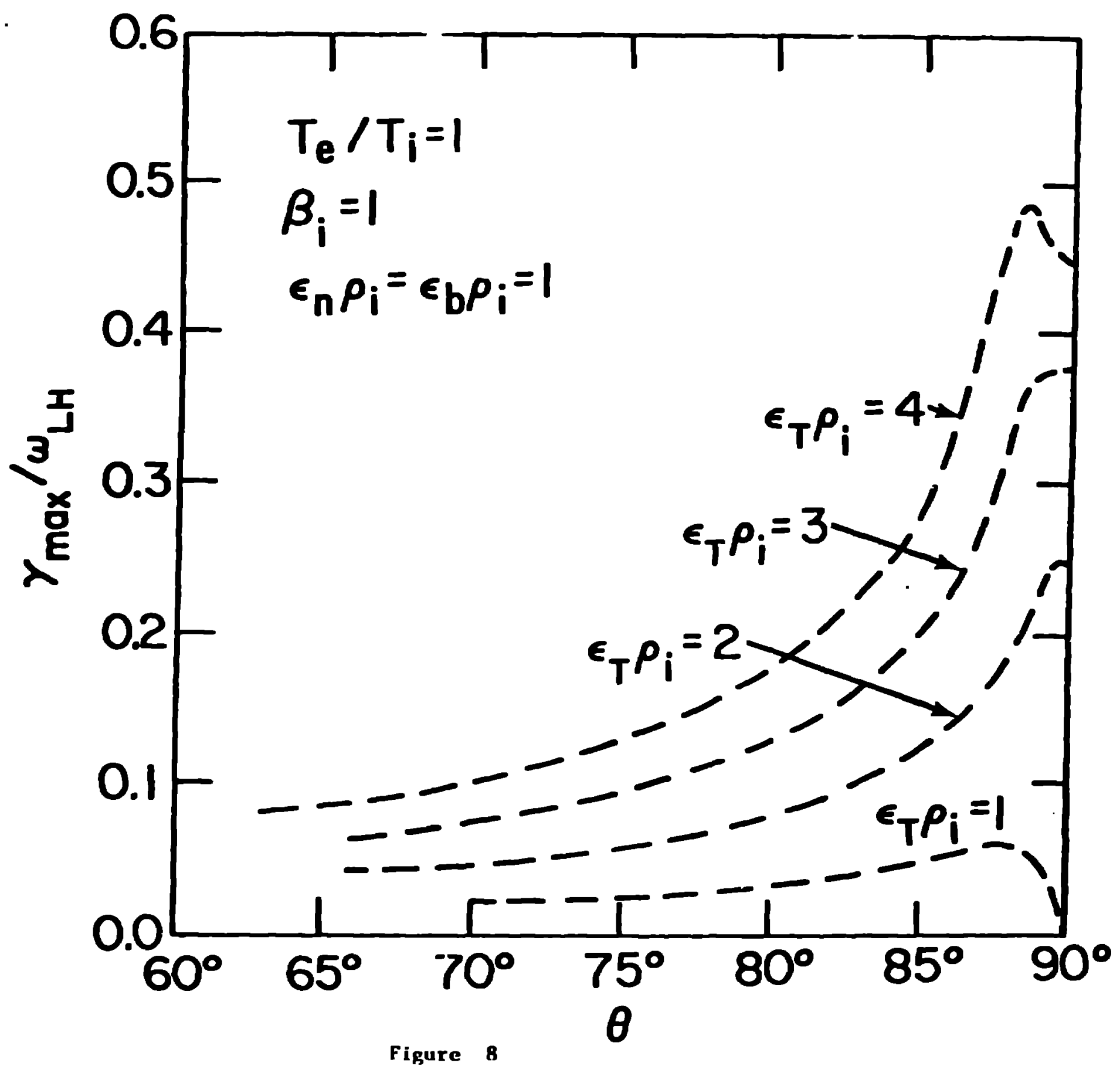



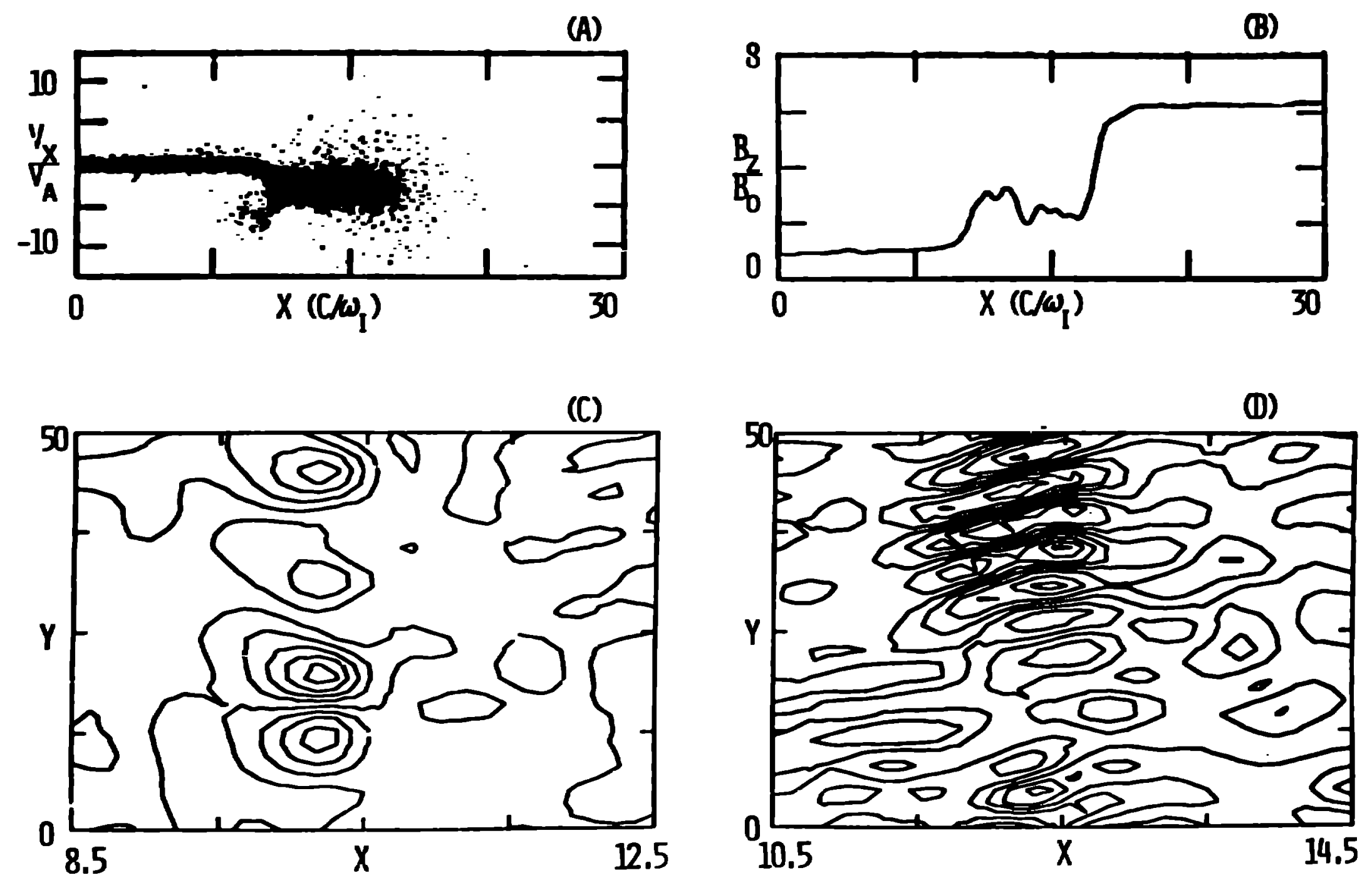

Figure ? 